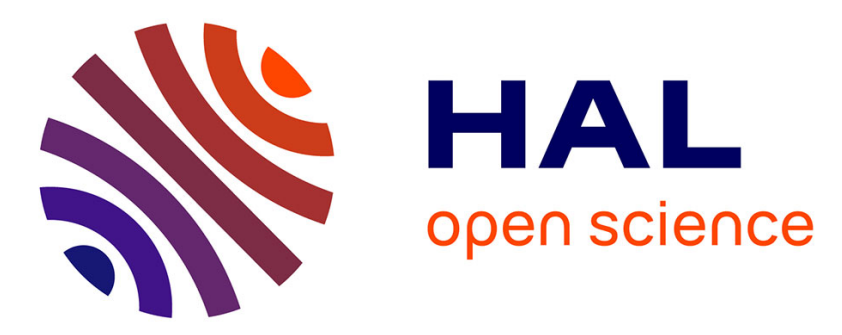

\title{
Characterization of xenobiotic metabolizing enzymes of a reconstructed human epidermal model from adult hair follicles
}

Daniel Bacqueville, Carine Jacques, Laure Duprat, Emilien L. Jamin, Beatrice Guiraud, Elisabeth Perdu, Sandrine Bessou-Touya, Daniel Zalko, Hélène

Duplan

\section{To cite this version:}

Daniel Bacqueville, Carine Jacques, Laure Duprat, Emilien L. Jamin, Beatrice Guiraud, et al.. Characterization of xenobiotic metabolizing enzymes of a reconstructed human epidermal model from adult hair follicles. Toxicology and Applied Pharmacology, 2017, 329, pp.190-201. 10.1016/j.taap.2017.05.040 . hal-01608588

\section{HAL Id: hal-01608588 \\ https://hal.science/hal-01608588}

Submitted on 26 May 2020

HAL is a multi-disciplinary open access archive for the deposit and dissemination of scientific research documents, whether they are published or not. The documents may come from teaching and research institutions in France or abroad, or from public or private research centers.
L'archive ouverte pluridisciplinaire $\mathbf{H A L}$, est destinée au dépôt et à la diffusion de documents scientifiques de niveau recherche, publiés ou non, émanant des établissements d'enseignement et de recherche français ou étrangers, des laboratoires publics ou privés. 


\section{Accepted Manuscript}

Characterization of xenobiotic metabolizing enzymes of a reconstructed human epidermal model from adult hair follicles

Daniel Bacqueville, Carine Jacques, Laure Duprat, Emilien L. Jamin, Beatrice Guiraud, Elisabeth Perdu, Sandrine BessouTouya, Daniel Zalko, Hélène Duplan

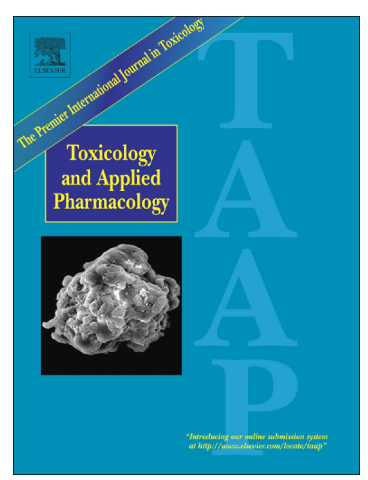

PII:

S0041-008X(17)30258-2

DOI: doi: 10.1016/j.taap.2017.05.040

Reference:

YTAAP 13975

To appear in:

Toxicology and Applied Pharmacology

Received date:

7 March 2017

Revised date:

10 May 2017

Accepted date:

30 May 2017

Please cite this article as: Daniel Bacqueville, Carine Jacques, Laure Duprat, Emilien L. Jamin, Beatrice Guiraud, Elisabeth Perdu, Sandrine Bessou-Touya, Daniel Zalko, Hélène Duplan, Characterization of xenobiotic metabolizing enzymes of a reconstructed human epidermal model from adult hair follicles. The address for the corresponding author was captured as affiliation for all authors. Please check if appropriate. Ytaap(2017), doi: 10.1016/j.taap.2017.05.040

This is a PDF file of an unedited manuscript that has been accepted for publication. As a service to our customers we are providing this early version of the manuscript. The manuscript will undergo copyediting, typesetting, and review of the resulting proof before it is published in its final form. Please note that during the production process errors may be discovered which could affect the content, and all legal disclaimers that apply to the journal pertain. 
Characterization of xenobiotic metabolizing enzymes of a reconstructed human epidermal model from adult hair follicles

Daniel Bacqueville ${ }^{1, *} \bullet$, Carine Jacques ${ }^{1, \bullet}$, Laure Duprat ${ }^{1}$, Emilien L. Jamin ${ }^{2}$, Beatrice Guiraud ${ }^{1}$, Elisabeth Perdu $^{2}$, Sandrine Bessou-Touya ${ }^{1}$, Daniel Zalko ${ }^{2}$, Hélène Duplan ${ }^{1}$

\section{Comple te affiliations:}

${ }^{1}$ Pierre Fabre Dermo-cosmétique, Service Pharmacologie Division 2 et Pharmacocinétique Cutané, Département Pharmacologie, Centre R\&D Pierre Fabre, 3 avenue Hubert Curien, Toulouse, France.

${ }^{2}$ Toxalim (Research Centre in Food Toxicology), Université de Toulouse, INRA, ENVT, INP-Purpan, UPS, Toulouse, France.

- Equal contribution

\section{Manuscript correspondence}

* Corresponding author:

Daniel Bacqueville

Tel.:+33 534506427

Fax: +33534503424

E-mail address: daniel.bacqueville@pierre-fabre.com 


\begin{abstract}
In this study, a comprehensive characterization of xenobiotic metabolizing enzymes (XMEs) based on gene expression and enzyme functionality was made in a reconstructed skin epidermal model derived from the outer root sheath (ORS) of hair follicles (ORS-RHE). The ORS-RHE model XME gene profile was consistent with native human skin. Cytochromes P450 (CYPs) consistently reported to be detected in native human skin were also present at the gene level in the ORS-RHE model. The highest Phase I XME gene expression levels were observed for alcohol/aldehyde dehydrogenases and (carboxyl) esterases. The model was responsive to the CYP inducers, 3-methylcholanthrene (3-MC) and $\beta$-naphthoflavone ( $\beta \mathrm{NF})$ after topical and systemic applications, evident at the gene and enzyme activity level. Phase II XME levels were generally higher than those of Phase I XMEs, the highest levels were GSTs and transferases, including NAT1. The presence of functional CYPs, UGTs and SULTs was confirmed by incubating the models with 7-ethoxycoumarin, testosterone, benzo(a)pyrene and 3-MC, all of which were rapidly metabolized within $24 \mathrm{~h}$ after topical application. The extent of metabolism was dependent on saturable and non-saturable metabolism by the XMEs and on the residence time within the model.
\end{abstract}

In conclusion, the ORS-RHE model expresses a number of Phase I and II XMEs, some of which may be induced by AhR ligands. Functional XME activities were also demonstrated using systemic or topical application routes, supporting their use in cutaneous metabolism studies. Such a reproducible model will be of interest when evaluating the cutaneous metabolism and potential toxicity of innovative dermocosmetic ingredients.

Key words: reconstructed human epidermis, hair follicle, cutaneous metabolism, gene expression, functional activity 
Abbreviations: alcohol dehydrogenases (ADH); aldehyde dehydrogenases (ALDH); aryl hydrocarbon receptor $(\mathrm{AhR})$; $\mathrm{APCI}$ source in the positive mode (PI-APCI); benzo(a)pyrene $(\mathrm{B}(\mathrm{a}) \mathrm{P})$; $\beta$-naphthoflavone $(\beta N F)$; carboxylesterase 1 and 2 (CES1/2); catechol-O-methyltransferase (COMT); cytochrome P450 (CYP); epoxide hydrolase (EPHX); esterase D (ESD); ESI source in the negative mode (NI-ESI); 7ethoxycoumarin (7-EC); ethoxyresorufin O-deethylase (EROD); flavin monooxidase (FMO); glutathione S-transferase (GST); High Resolution Mass Spectrometry (HRMS); hydroxysteroid (17- $\beta$ dehydrogenase 10 (HSD17B10); hydroxycoumarin (HC); long-chain-fatty-acid-CoA ligase 1 (ACSL1); 3methylcholanthrene (3-MC); N(alpha)-acetyltransferase 20 (NAA20); N-acetyl transferase (NAT); Organization for Economic Cooperation and Development (OECD); outer root sheath-derived reconstructed human epidermis (ORS-RHE); prostaglandin-endoperoxide synthase (PTGS2); real time reverse transcription PCR (RT-qPCR); spermine N1-acetyltransferase 1 (SAT1); sulfotransferase (SULT); ubiquitin carboxyl-terminal esterase L3 (UCHL3); UDP glucuronosyltransferase (UGT); xenobiotic metabolizing enzymes (XMEs). 


\section{$1 \quad$ Introduction}

The outer root sheath-derived reconstructed human epidermal (ORS-RHE) model is a three-dimensional human skin equivalent model engineered from adult undifferentiated keratinocytes from ORS cells of hair follicles. This model was developed in order to establish a cost-effective and reproducible in vitro human epidermal model that could be customized according to specific assay needs (Guiraud et al., 2014). The use of ORS derived keratinocytes affords a number of advantages over other RHE models, including the ease of the rapid and non-invasive sample collection, the ability to select a particular donor (gender, age, healthy or diseased) and, moreover, the selection of adult donors, as opposed to neonatal donors that are commonly used in commercial models. The ORS-RHE model was shown to be a good and reproducible alternative to native human epidermis, such that the architecture, general stratification and localization of differentiation markers were similar to those of native epidermis (Guiraud et al., 2014). This ORS-RHE model has been shown to be a good alternative to human skin for studying the effects of UV radiation (e.g. bipyrimidine photoproduct production, repair and induction of apoptosis) and investigating the sunscreen genoprotection (Bacqueville et al., 2015). Here, our intention was to extend the use of the ORS-RHE model to metabolism studies in the same way as previous reports using RHE models, such as SkinEthic, Phenion $^{\circledR}$ Full-Thickness skin model and EpiDerm ${ }^{\mathrm{TM}}$, that support their applicability to this purpose by characterizing the functional activities of several Phase I and II xenobiotic metabolizing enzymes (XMEs) in these models (Eilstein et al., 2015; Jäckh et al., 2011).

The rate of percutaneous absorption of some compounds is known to be influenced by skin metabolism (Lockley et al., 2004; Jacques et al., 2010a), and as compounds penetrate the skin, they may be subject to metabolism, which can detoxify them to more water-soluble metabolites or bioactivate them to reactive metabolites (Bronaugh and Stewart, 1985, Oesch et al., 2007 and 2014). Therefore, in order to help interpret toxicity endpoints, it is important to characterize the metabolic capacity of the skin models used in bioassays. In this study, we aimed to characterize as precisely as possible the metabolic capabilities of the ORS-RHE model To this end, we first investigated the overall basal XME gene expression profile of 
the ORS-RHE model using RT-qPCR analysis of more than 90 Phase I and 70 Phase II XME genes. Since the most relevant route of exposure to the skin is topical, it is important to show that RHE models can be used to investigate topically applied chemicals. This is also of importance since the metabolic capacity of such models could be altered during the course of topical treatment with a test compound (Hewitt et al., 2013). Therefore, we measured the effect of two known AhR ligands, namely $\beta$-naphthoflavone ( $\beta$ NF) and 3-methylcholanthrene (3-MC), on XME gene expression after systemic (added to the culture medium, located below the model) and topical (added to the upper surface of the model) application. The expression of a XME gene does not necessarily indicate that the corresponding XME is functional. In addition, we confirmed induction effects by incubating control and inducer-treated skin models with the CYP1A1/2 and CYP1B1 selective substrate, ethoxyresorufin.

In addition to analyzing the XME profile of the ORS-RHE model, we complemented this by investigating functional XME activities by measuring the metabolism of four test chemicals with varying metabolic pathway complexities. The two endpoints (gene expression and functional metabolism) were compared using similar timepoints ( $24 \mathrm{~h}$ ). Additional timepoints (48 and $72 \mathrm{~h}$ ) were added for functional metabolic studies, to capture the kinetics of metabolism. The test chemicals were 7-ethoxycoumarin (7-EC), testosterone, B(a)P, and 3-MC. 7-EC represents a chemical with a simple metabolite profile involving both Phase I and II sequential pathways (De Kanter et al., 1999). The skin is known to be able to metabolize steroids (Haag et al., 2012); therefore, we selected testosterone as a model of an endogenous steroid and a well-established diagnostic substrate for CYP activities. This substrate can also be metabolized through reductive pathways. Since the reductive capacity of the skin has previously been reported to be good (van Eijl et al., 2012) testosterone represents an ideal substrate to confirm the functional oxido-reductive capacity of the model. Testosterone is also specified in the Organization for Economic Cooperation and Development (OECD) adopted guideline 28 (OECD, 2004a) and a corresponding technical guidance document (OECD, 2004b) to describe methods assessing drug absorption as one of the model compounds to develop skin alternative models. $\mathrm{B}(\mathrm{a}) \mathrm{P}$ is a known genotoxic 
compound which toxicity relies on a CYP450-dependent bioactivation, into ultimate DNA reactive metabolites (Conney et al., 1994). B(a)P has been also shown to induce EROD activities in the epidermal model, Epiderm ${ }^{\mathrm{TM}}, 24 \mathrm{~h}$ after topical application (Götz et al., 2012), suggesting it induces its own metabolism and that this model responds to CYP1 induction. B(a)P is also detoxified by GSTs, SULTs and UGTs, so it is important to understand the balance of metabolism of such a genotoxic compound in human skin, especially to help interpret negative outcomes in genotoxicity assays using skin epidermal models (Aardema et al., 2013). 3-MC is a direct genotoxin and is metabolized via Phase I and II pathways. It was used to investigate the inducibility of XMEs in ORS-RHEs and therefore it was of interest to measure its metabolism alongside its induction effects.

These studies aimed to provide a comprehensive characterization of the XMEs present in the novel ORSRHE model by analyzing both gene expression profiles (PCR) and functional activities (EROD activity and test chemical metabolism). The suitability of the model for compound metabolism assays was evaluated, as well as the application of test compounds by the systemic and topical routes.

\section{$2 \quad$ Materials and methods}

\subsection{Chemicals}

7-ethoxy $\left[3-{ }^{14} \mathrm{C}\right]$-coumarin, $\left[\mathrm{U}-{ }^{14} \mathrm{C}\right]$-bisphenol A, $\left[5,6-{ }^{14} \mathrm{C}\right]$ benzo(a)pyrene $\left[{ }^{14} \mathrm{C}-\mathrm{B}(\mathrm{a}) \mathrm{P}\right],\left[4,7-{ }^{14} \mathrm{C}\right]-$ testosterone with specific activities of 2, 2.074, 2 and $2.03 \mathrm{GBq} / \mathrm{mmol}$, respectively, were purchased from Amersham Biosciences (Buckinghamshire, UK). 3-Methylcholanthrene- $\left[{ }^{3} \mathrm{H}\right]$ was purchased from Moravek Biochemicals (Brea, United States). Unlabeled 7-EC, B(a)P, 3-MC and testosterone, purchased from Sigma-Aldrich (St Quentin Fallavier, France) had a purity greater than $98.5 \%$.

Benzo(a)pyrene-r-7,t-8,t-9,t-10-tetrahydrotetrol, benzo(a)pyrene-cis-7,8-dihydrodiol, benzo(a)pyrene-cis4,5-dihydrodiol, benzo(a)pyrene-1,6-dione, benzo(a)pyrene-3,6-dione, benzo(a)pyrene-7,8-dione, 8hydroxybenzo(a)pyrene, 9-hydroxybenzo(a)pyrene, 3-hydroxybenzo(a)pyrene, 7-hydroxybenzo(a)pyrene 
were obtained from the National Cancer Institute Chemical Carcinogen Reference Standards Repository (Kansas City, MO, USA) and were used as reference compounds.

Testosterone reference metabolites were from Sigma-Aldrich (St Quentin Fallavier, France):2 $\beta$ hydroxytestosterone, $6 \beta$-hydroxytestosterone, $7 \alpha$-hydroxytestosterone, $11 \beta$-hydroxytestosterone, $16 \alpha$ hydroxytestosterone, 11-ketotestosterone, 1-dehydrotestosterone, 4-androstene-3,17-dione, 4-androsten-

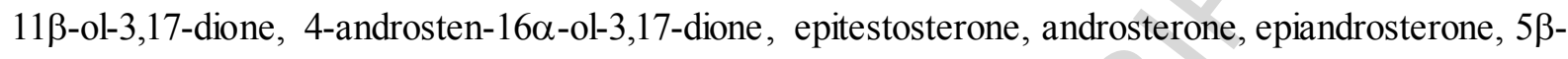

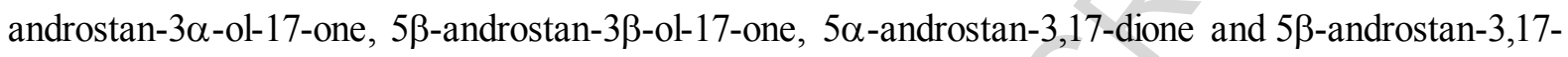
dione.

Other chemicals and solvents (analytical grade) were purchased from the following sources: ammonium acetate, sodium acetate, phosphate buffer $(0.01 \mathrm{M})$ and sodium hydroxide, from Sigma-Aldrich; acetonitrile and ethyl acetate from Scharlau chemie S.A. (Barcelona, Spain); ethanol and acetic acid from Merck (Briare-Le-Canal, France). Ultrapure water from a Milli-Q system(Millipore, Saint Quentin en Yvelines, France) was used for HPLC mobile phase preparations. Dulbecco's Modified Eagle Medium (DMEM) and L-glutamine were obtained from Gibco ${ }^{\mathrm{TM}}$ (Cergy Pontoise, France). The antibiotics (streptomycin/penicillin, gentamycin) and the antifongic (fungizone) used in the culture media were purchased from Sigma-Aldrich.

\subsection{Pre paration of reconstituted human e pidermis}

Human epidermis was reconstructed using ORS keratinocytes isolated from hair follicles obtained from three healthy Caucasian volunteers who had given their informed consent. The tissues were engineered inhouse according to the protocol described by Guiraud et al. (2014). Figure 1A provides an overview of the culture of the ORS-RHE tissues and the structure of the tissues at the time of incubation (histology).

Briefly, plucked hair follicles were explanted on a microporous membrane of a cell culture insert (Costar, 
Corning, New York, US) with post-mitotic human dermal fibroblasts sub-lethally treated with mitomycin $\mathrm{C}$ on the underside. Follicles were submerged in the medium after 6 days and then cultured for a further 2 to 3 weeks before ORS cell harvesting and long-term storage. The growth medium $(0.5 \mathrm{ml}$ and $1 \mathrm{ml}$ per incubation for EROD activity and qPCR/metabolism assays, respectively) contained DMEM/Ham's F12 (3:1) supplemented with $10 \%$ fetal calf serum, epidermal growth factor, hydrocortisone, adenine, triiodothyronine, insulin, amphotericin and antibiotics and was refreshed three times a week. For tissue reconstruction, the ORS cells were then plated at a density of $0.3 \times 10^{6}$ cells $/ \mathrm{cm}^{2}$ on cell culture inserts, again with post-mitotic human dermal fibroblasts as described previously. After 2-3 days, the keratinocytes reached confluence, at which time the cultures were lifted to the air-medium interface in order to differentiate the tissue and to form a functional stratum corneum (insert picture). After 16 days of differentiation, the tissues were treated with the test compound.

\subsection{Measurement of XME gene expression}

Figure 1B provides an overview of the culture of the RHE tissues and the incubation conditions (systemic or topical). For qPCR analysis, ORS-RHE models $\left(1.12 \mathrm{~cm}^{2}\right.$ cultured with $1 \mathrm{ml}$ supplemented DMEM medium) were treated with $25 \mu \mathrm{M} \beta \mathrm{NF}$ in DMSO to the medium (systemic application) or of 100 nmoles $/ \mathrm{cm}^{2} 3-\mathrm{MC}$ in acetone to the surface of the model (topical application). The control treated tissues were DMSO (systemic application) or acetone (topical application). RNA was isolated from the ORSRHE models $24 \mathrm{~h}$ after xenobiotic treatment and the XME gene expression profiles were measured using real time reverse transcription PCR (RT-qPCR). The $\mathrm{RT}^{2}$ Profiler ${ }^{\mathrm{TM}}$ PCR Arrays human drug metabolism Phase I and Phase II enzymes were used according to the supplier's instructions (SA Biosciences/Qiagen). The panel of the metabolic genes is available in Figure 2 and Supplementary Table 1.

Total RNA was extracted using the RNeasy Mini kit and RNAse-free DNAse I set (Qiagen), and quantified using a NanoDrop ND-1000 spectrophotometer. Then, $1 \mu \mathrm{g}$ RNA was reverse transcripted into cDNA by using the $\mathrm{RT}^{2}$ first strand kit and an Applied Biosystems 2720 Thermal Cycler. The Phase I and 
II enzyme arrays were run on a iCycler $\mathrm{iQ}^{\mathrm{TM}}$ real time PCR detection system (Bio-Rad laboratories). The RT $^{2}$ SYBR Green Mastermix containing HotStart DNA Taq Polymerase enzyme and other components preventing non-specific amplification and reference dyes was mixed with cDNA and amplification was performed with a $10 \mathrm{~min}$ hot start at $95^{\circ} \mathrm{C}$, followed by 40 cycles of $95^{\circ} \mathrm{C}$ for $15 \mathrm{sec}$ and $60^{\circ} \mathrm{C}$ for $1 \mathrm{~min}$. A dissociation curve was performed after running to check single amplicons. Assays for 5 housekeeping genes were included in the arrays for normalization of data, and the results were analyzed according to the $\Delta \Delta \mathrm{C}_{\mathrm{T}}$ method by using the web-based $\mathrm{RT}^{2}$ Profiler ${ }^{\mathrm{TM}}$ PCR Array Data Analysis Software. A $\mathrm{C}_{\mathrm{T}}$ value of 32 or more was considered to be absent, and fold-changes of gene expression were obtained from different reconstructed epidermis $(n=3-8)$ depending the xenobiotic treatments.

\subsection{Measure ment of functional XME activities}

\subsubsection{Induction of ethoxyresorufin O-deethylase (EROD) activity}

ORS-RHE models $\left(0.33 \mathrm{~cm}^{2}\right.$ cultured with $0.5 \mathrm{ml}$ supplemented DMEM medium) were treated with nontoxic concentrations of $\beta \mathrm{NF}(25 \mu \mathrm{M})$ or 3-MC $(10 \mu \mathrm{M})$ in DMSO to the medium (systemic application) or of $100 \mathrm{nmoles} / \mathrm{cm}^{2} 3-\mathrm{MC}$ or $\beta \mathrm{NF}$ in acetone to the surface of the model (topical application, $10 \mu \mathrm{l} / \mathrm{cm}^{2}$ ) (see Figure 1B). The control tissues were treated with DMSO (systemic application) or acetone (topical application). The concentrations of the inducers and the measurement of EROD activity were based on the method previously described by Harris et al. (2002), such that, on a $\mu \mathrm{g} / \mathrm{cm}^{2}$ basis, topical doses are approximately 5-fold higher than systemically applied doses. After incubation and PBS washing, the ORS-RHE modelwere placed in a 24-well plate containing $500 \mu \mathrm{L}$ EROD buffer containing $3.4 \mu \mathrm{M}$ ethoxyresorufin and $33 \mu \mathrm{M}$ dicoumarol freshly prepared in culture medium. The incubation was carried out for $1 \mathrm{~h}$ at $37^{\circ} \mathrm{C}$, after which fluorescence was measured using a multiplate reader Mithras LB940 (Berthold technologies) with an excitation wavelength of $530 \mathrm{~nm}$ and emission wavelength of $590 \mathrm{~nm}$. The resorufin was quantified directly from tissue culture medium according to a standard curve (1.5 to 100 pmoles). Finally, the epidermis was lyzed by using $0.5 \mathrm{M} \mathrm{NaOH}$ and total proteins were assayed with a 
micro BC Assay protein quantification kit (Uptima) in order to measure EROD activity, which was expressed in pmole/mg/min. Experiments were performed from epidermis reconstructed from 3 batch donors, each assayed in triplicate $(n=9)$.

\subsubsection{Test compound me tabolism}

ORS-RHE models $\left(1.12 \mathrm{~cm}^{2}\right.$ cultured with $1 \mathrm{ml}$ supplemented DMEM medium) were incubated with 1 to $4 \mathrm{nmoles} / \mathrm{cm}^{2}$ of test compound in acetone $\left(10 \mu \mathrm{l} / \mathrm{cm}^{2}\right)$ to the surface of the model (topical application). Test compounds were radiolabelled 7-EC, testosterone, $\mathrm{B}(\mathrm{a}) \mathrm{P}$ and 3-MC, adjusted with unlabeled 7-EC, testosterone, $\mathrm{B}(\mathrm{a}) \mathrm{P}$ and 3-MC to reach the required dose. Culture media were collected at $24 \mathrm{~h}, 48 \mathrm{~h}$ and $72 \mathrm{~h}$ and were stored at $-20^{\circ} \mathrm{C}$ until the analysis. All incubations were carried out in triplicate ( 3 batches). Compartmental analysis for B(a)P, 7-EC and testosterone was performed as previously described by Jacques et al (2010 a, b and 2014). Briefly, ORS-RHE surfaces, tissue culture inserts and wells were washed twice with acetonitrile or methanol, according to the physicochemical properties of the compound studied. ORS-RHE models were dissolved in $4 \mathrm{ml}$ of solvable overnight (Perkin Elmer, France). Radioactivity in culture media, RHE extracts and washing solutions, was quantified by scintillation counting to obtain the mass balance. Metabolite analyses were performed by radio-HPLC and mass spectrometry, as previously described by Jacques et al. (2010 a and b and 2014) for 7-EC, B(a)P and testosterone. For 3-MC, the HPLC system consisted of an Agilent 1100 (France) associated with a 250×4.6 mm, $(5 \mu \mathrm{m})$ Zorbax Sb-C18 column (Agilent, Interchim, Montluçon, France) protected by a Kromasil C18 guard precolumn (Interchim, Montluçon, France). Mobile phases used at a flow rate of 1 $\mathrm{ml} / \mathrm{min}$, consisted of A: ammonium acetate $(20 \mathrm{mM}, \mathrm{pH} 3.5)$ : acetonitrile (95:5; v/v) and $\mathrm{B}$ : acetonitrile. The temperature of the column was maintained at $30^{\circ} \mathrm{C}$ and the following gradient was used: 0 min $0 \% \mathrm{~B}$, $5 \min 10 \%$ B, $15 \min 18 \%$ B, $28 \min 18 \%$ B, $33 \min 28 \%$ B, 40 min $28 \%$ B, $45 \min 40 \%$ B, 50 min $50 \%$ B, $55 \min 62.5 \%$ B, $65 \min 100 \%$ B, $70 \min 100 \%$ B, $71 \min 0 \%$ B, $75 \min 0 \%$ B. ${ }^{3} \mathrm{H}-3-\mathrm{MC}$ and related metabolites separated by HPLC were monitored by on-line radioactivity detection using a Flo-one A500 (Perkin Elmer, France). The scintillation cocktail used for Flo-one detection was Ultima Flow M (Packard 
Instruments). 3-MC and its metabolites were quantified by integrating the area of the radiochromatographic peaks.

Mass spectrometry analyses of 3-MC metabolites were performed using an LTQ-Orbitrap-XL mass spectrometer (Thermo Fisher, Les Ulis, France) operating either with an ESI source in the negative mode (NI-ESI) or an APCI source in the positive mode (PI-APCI). A post column split diverted $25 \%$ of the mobile phase to the ion source. Since reference metabolites of 3-MC, operating ESI source parameters were optimized from reference metabolites of benzo(a)pyrene which display similar structures, and were state as follow: spray voltage $-2.5 \mathrm{kV}$, sheath gas (N2) 30 au, auxiliary gas $\left(\mathrm{N}_{2}\right) 10$ au and capillary temperature $360^{\circ} \mathrm{C}$. Optimal APCI source conditions were obtained from 3-MC analysis were set as follows: vaporizer temperature $300^{\circ} \mathrm{C}$, Corona discharge $4 \mu \mathrm{A}$, sheath gas $\left(\mathrm{N}_{2}\right) 60$ au, auxiliary gas $\left(\mathrm{N}_{2}\right)$ $25 \mathrm{au}$, and capillary temperature $150^{\circ} \mathrm{C}$. The Orbitrap mass analyzer was used at a resolution of 60,000 .

\section{$3 \quad$ Results and discussion}

\subsection{Basal gene expression of XMEs}

The basal gene expression of a panel of gene targets for Phase I and II metabolism in ORS-RHE models treated systemically with DMSO in the medium (1\% v/v final concentration) is shown in Figure 2 . Basal expression of Phase I XMEs after systemic application of DMSO was very similar to that in ORS-RHEs after topical application of $10 \mu \mathrm{l} / \mathrm{cm}^{2}$ acetone, suggesting that neither the solvent nor the method of application markedly affected the basalexpression of XMEs. The levels of expression were assigned according to the $\mathrm{Ct}$ (which are also shown in Supplementary Table 1); whereby "no expression" was assigned to samples for which the $\mathrm{Ct}$ was $>32$; whereas, strong expression was assigned to samples with a $\mathrm{Ct}<25$ and "weak" to "good" expression were between these values.

\subsubsection{Phase I XMEs}

In general, the variety of genes expressed as well as their levels of expression were globally lower 
for CYP than for non-CYP phase I XMEs, especially, aldehyde dehydrogenases (ALDH), for which the expression levels of $10 \mathrm{ALDH}$ isoforms were good $(\mathrm{Ct}<30)$ or strong $(\mathrm{Ct}<25)$ (Figure $2 \mathrm{~A}$ and Supplementary Table 1). Interestingly, only one of the seven alcohol dehydrogenases (ADH) measured was expressed in the RHE tissues, namely ADH5. It has been reported that ADH3 is the most abundant isoform in skin (Cheung et al. 1999). Since the gene panel used was developed by the supplier for toxicological assays, especially for the reference organ:liver, ADH3 was not included in this gene panel and consequently it was not investigated in our study. Although our skin model includes a fibroblast feeder layer on the underside of the transwell insert, which could affect the overall XME profile by contributing to the gene expression profile, it appeared not to do so since selectively dermal XMEs were not present in these ORS-RHE models. For example, ADH1B was absent in the RHE models and this finding is consistent with its exclusively dermal location (Luu-The et al., 2009). NQO1 is a cytoplasmic dehydrogenase that reduces quinones to hydroquinones. It is present in native human skin and is thought to help to protect the epidermis against oxidative stress (Hu et al., 2010). The NQO1 gene was also well expressed in ORS-RHE tissues. In addition to the good expression of dehydrogenases, UCHL3 (ubiquitin carboxyl-terminal esterase L3, a protease), HSD17B10 (hydroxysteroid 17- $\beta$ dehydrogenase 10), expressed in the basement epidermis and involved in estrogen formation/metabolism (Hikima and Maibach, 2007) and ESD (esterase D, involved in the recycling of sialic acids) were also strongly expressed in the ORS-RHE tissues. The epoxide hydrolase gene, EPHX1, is preferentially expressed in the dermis but is also present in the epidermis of native human skin (Luu-The et al., 2009). Likewise, this gene was also expressed at low (DMSO treated) and good (acetone treated) levels in ORS-RHE tissues. The expression of this XME is important since this enzyme is involved in the detoxification via hydrolysis of polycyclic aromatic hydrocarbons e.g. 3-MC and $\mathrm{B}(\mathrm{a}) \mathrm{P}$, via hydrolysis, and plays an important role in the inactivation of many reactive epoxides (Benhamou et al., 1998). Carboxylesterase 1 and 2 (CES1/2) also play an important role in the hydrolysis of a large number of structurally diverse drugs. They were expressed at good levels in ORS-RHE models. CES1 is the major hydrolase in human liver; whereas, CES2 is responsible for the majority of hydrolase activity in the small intestine but both are responsible 
for the metabolism of multiple drugs (Imai, 2006 and Oesch et al., 2007). Both of these isoforms are also reported to be present in native human skin; whereas, the expression of CES3 is lacking (Hu et al., 2010). Accordingly, the CES3 was not expressed in ORS-RHE models.

Of the FMOs, only FMO4 was found to be present in measureable amounts in the ORS-RHE tissues. This is of interest because it is reported that the expression of this XME is differently in the epidermis and dermis (Luu-The et al., 2009, Wiegand et al., 2014). While it is expected that FMO2 and FMO3 would be lacking from the RHE models because they are selectively expressed in the dermis, FMO1, FMO4 and FMO5 have been reported to be present in the epidermis or whole skin of native skin (Luu-The et al., 2009, Hu et al., 2010). The expression of FMO genes in RHE models has previously been reported to be affected by the culture medium and the presence of fibroblasts which secrete inhibitory factors (Luu-The et al., 2009). In addition, there is a large variation in the presence of FMOs in skin from different donors, whereby only half the skin samples from individuals have been shown to express FMO1, 3, and 4 mRNA (Oesch et al., 2014).

The expression of the major hepatic phase I XMEs, namely CYP1A2, CYP2C9/18/19 and CYP3A4 were found to be absent or present only at low levels in ORS-RHE models and only a few of the 42 target CYP genes were present in measureable levels (weak or good expression). These genes were CYP1B1, CYP2C18, CYP2R1, CYP2S1, CYP3A5, CYP4B1, CYP4F2, CYP4F3, CYP4F11, CYP7B1, CYP26B1 and CYP27B1. In previous studies, all of these genes, except CYP4F11, were found to be expressed in native whole skin tested by two other laboratories (Luu-The et al., 2009, Hu et al, 2010). CYP1B1 (which is absent in adult human liver (Edwards et al., 1998)), CYP4B1 and CYP26B1 were also reported to be strongly expressed compared to other CYPs in native human skin (Luu-The et al., 2009, Hu et al., 2010, Wiegand et al., 2014). Notable XMEs that were not expressed in ORS-RHE models were CYP1A1, CYP1A2 and CYP2B6; however, these were all reported to be expressed at very low levels in native human skin from one or more donors (Luu-The et al., 2009, Wiegand et al., 2014, Hu et al., 2010) , and 
were reported not to be expressed in human keratinocytes (Saeki et al 2002) and human skin (Oesch et al., 2014). CYP2D6 is reported to be a major CYP detected at the mRNA level in native human skin (Oesch et al., 2014). In our study, it was found to be expressed only at very low levels in DMSO-treated control models and not at all in topically applied acetone models (Supplementary Table 1). This may reflect the polymorphic nature of this CYP. To further check this, additional studies using CYP2D6-selective substrates (e.g. bufuralol or dextromethorphan) should be conducted to determine whether this CYP exhibits any functional activity in the ORS-RHE models. CYP3A4 expression appears to be donor dependent since it was absent in the ORS-RHE tissues measured here and in native skin from one donor (Hu et al., 2010) but present in native skin from three other donors (Wiegand et al., 2014). As with native skin, CYP3A5 was present at the gene level in the ORS-RHE models but not the fetal form of this CYP, namely CYP3A7.

\subsubsection{Phase II XMEs}

There were a number of Phase II XMEs expressed at significant levels in RHE tissues (Figure 2B). The most predominantly expressed GST was GSTP1 $(\mathrm{Ct}=20.5)$, which is known to be the major GST isoform expressed in the skin (Luu-The et al., 2009). All GSTs play an important role in the detoxification of reactive oxygen species such as that induced by UVB radiation (Black et al., 2008). Other cytosolic and microsomal GST isoforms were also present at good levels and have also shown to be present in native skin by others (Hu et al., 2010). SULT2B1, SULT1A3, SULT1E1 and thiosulfate sulfurtransferase (rhodanese, TST) were all expressed in good levels in ORS-RHE tissues; however, other sulfurtransferase genes targeted were undetectable. All the UGT isoforms found to be expressed in our model do belong to the UGT1A family, notably, UGT1A10, which is reported to be affected by the complexity of the skin model such that it is absent in monolayers of keratinocytes but present in 3D epidermal and full-thickness models derived from the same donors (Wiegand et al., 2014). The expression of $\mathrm{N}$-acetyl transferases (NATs) is known to be organ-specific such that NAT1 is preferentially expressed and has a higher functional activity in the skin than in the liver (Hu et al., 2010, Kawakubo et al., 1990). In keeping with 
this, the presence of NAT1 but the absence of NAT2 in the ORS-RHE was confirmed in our studies.

Other strongly expressed Phase II XME genes were ACSL1 (Long-chain-fatty-acid-CoA ligase 1, involved in lipid metabolism), COMT (catechol-O-methyltransferase), SAT1 (spermine N1acetyltransferase 1) and NAA20 (N(alpha)-acetyltransferase 20). The expression of COMT in skin has been suggested to be a surprising occurrence since this enzyme is involved in the metabolism of neurotransmitters and catechol hormones (Luu-The et al., 2009); however, we and others (Hu et al., 2010) also noted a strong expression of this enzyme, suggesting its presence is important in skin metabolism. SAT1 catalyzes the acetylation of spermidine and spermine, and is involved in the regulation of the intracellular concentration of polyamines and their transport out of cells.

\subsection{Induction of Phase I XME expression}

A comparison of the expression of phase I XMEs in ORS-RHE models with that $24 \mathrm{~h}$ after topical application of 3-MC or systemic application of $\beta-\mathrm{NF}$ is shown in Figure 3.

The $\mathrm{Ct}$ values and the statistical analysis for control and inducer-treated models are shown in Supplementary Table 1. A biologically relevant induction response was called when a gene was significantly $(\mathrm{P}<0.05)$ increased by more than 2 -fold and when the induced expressed level was greater than a $\mathrm{Ct}$ of 32. $\beta \mathrm{NF}$ and 3-MC are ligands for $\mathrm{AhR}$ and $\mathrm{AhR}$ regulates a number of Phase I XMEs, notably CYP1A and CYP1B1 isoforms ( $\mathrm{Li}$ et al. 1998). In line with this, there was a selective and significant $(\mathrm{P}<0.05)$ induction of CYP1A1 and CYP1B1 expression in ORS-RHE models treated with both $\beta \mathrm{NF}$ and 3-MC (Figure 3). Despite CYP1A1 being expressed at very low levels it was readily induced by $\beta \mathrm{NF}$ (133-fold) and 3-MC (250-fold) to clearly measurable levels. The response was much higher than that of CYP1B1 (13.9-fold by $\beta \mathrm{NF}$ and 11.9-fold by 3-MC), which was most likely due to the very low level of expression of CYP1A1 in solvent treated tissues. 
The induction of CYP1A1 and CYP1B1 at the gene level was confirmed at the functional level by incubating control and treated ORS-RHE tissues with the CYP1A1/2 and CYP1B1 selective substrate, ethoxyresorufin, $24 \mathrm{~h}$ after the start of induction with $\beta \mathrm{NF}$ or 3-MC (Figure 4). EROD activity was undetectable in ORS-RHE models treated topically or systemically with vehicle control solvents (DMSO or acetone, respectively). By contrast, EROD activity was measurable in ORS-RHE tissues from one or more batches treated topically and systemically with $\beta \mathrm{NF}$ or 3-MC. The extent of induction by inducers was higher and more consistent across donors in systemically treated ORS-RHE tissues than when they were topically applied. This could likely be due to difference in the bioavailability of the inducers such that less of the dose penetrated the ORS-RHE when applied topically (even though the theoretical dose was higher in topical applications). In addition, the induction response was higher using 3-MC than $\beta \mathrm{NF}$, which could be due to a higher affinity of 3-MC for AhR (despite the lower dose of 3-MC (10 $\mu \mathrm{M})$ compared to $\beta \mathrm{NF}(25 \mu \mathrm{M}))$.

A number of additional genes were induced by either $\beta \mathrm{NF}$ or 3-MC (but never by both inducers), namely, CYP4F3, ALDH3A1 and NQO1 by the systemic application of $\beta$ NF and PTGS2 by topically applied 3MC (2.2-fold, $\mathrm{P}<0.05)$. ALDH3A1 was significantly induced $(\mathrm{P}<0.001)$ by $>2$-fold following the systemic or topical application of both inducers (Figure 3); however, the induction was only considered to be biologically relevant after the systemic application of $\beta \mathrm{NF}$ since the induced level was below a $\mathrm{Ct}$ of 32. By contrast, although the topical application of 3-MC caused a significant induction of this gene (2.64fold), the induced level was still below the cut-off value considered to be biologically relevant (Ct was 32.34).

There were two other genes that were induced by more than 2-fold (ALDH1A3 and CY4F12) by $\beta$ NF; however, the increase did not reach statistical significance (P values: 0.323and 0.245, respectively) and/or 
the induced level was not biologically relevant (Ct was $\sim 32$ for CYP4F12).

\subsection{Induction of Phase II XME expression}

A comparison of the expression of phase II XMEs in ORS-RHEs with that $24 \mathrm{~h}$ after topical application of 3-MC or systemic application of $\beta$-NF is shown in Figure 5. The Ct values and the statistical analysis for control and inducer-treated models are shown in Supplementary Table 1. Unlike Phase I XMEs, there was only one type of Phase II XME genes that was induced by $\beta$ NF and 3-MC, namely UGTs (UGT1A3/5/6/7/8 and 10), and the extent of induction was also relatively low (2- to 5-fold) compared to CYP1A1 and CYP1B1 induction. The lower induction of UGTs compared to CYPs has also been reported by others using hepatocytes (Soars et al., 2004). The responses were higher after systemic application of $22 \mathrm{nmoles} / \mathrm{cm}^{2} \beta \mathrm{NF}$ (3.8-4.6-fold) than after topical application of $100 \mathrm{nmoles} / \mathrm{cm}^{2} 3$-MC (2.6-2.9-fold).

There were two phase II XMEs that were down-regulated by more than 2-fold by topically applied 3-MC, namely INMT and SULT1A1; however, this effect was considered not to be biologically relevant because change was not significant from control treated ORS-RHE models.

\subsection{Me tabolism of model substrates after topical application}

Having characterized the Phase I and II XME gene expression in ORS-RHE tissues, we then investigated whether this correlated with functional XME activities by incubating them with four test compounds known to be metabolized by phase I and/or II XMEs. All four test chemicals are known to penetrate through the skin (from the studies presented here and from previous reports (Jacques et al., 2010a and b and 2014)) and were therefore applied topically. The incubations included three time points $(24,48$ and 72 h); however, in order to compare the functional profiles with the gene expression analysis described above (which was measured after $24 \mathrm{~h}$ ), we have expressed the dose-dependent effects using $24 \mathrm{~h}$ incubations. It was also considered to be a suitable time point since all of the 4 model substrates were found to be 
extensively metabolized after $24 \mathrm{~h}$ (Supplementary Figure 1).

\subsubsection{7-Ethoxycoumarin (7-EC)}

The main metabolites of 7-EC produced in recombinant human liver microsomes are produced via CYP1A1 and CYP2E1 (and a minor amount via CYP1A2 and CYP1B1) mediated O-deethylation to hydroxycoumarin (HC) (Shimada et al., 1997), ), with a subsequent conjugation of the intermediate metabolite into HC-glucuronide and HC-sulfate (De Kanter et al., 1999). These three metabolites were produced in the ORS-RHE model, with the major metabolite being HC-glucuronide (Figure 6). Since basal CYP2E1 expression was absent in these ORS-RHE models, the CYP responsible for the biotransformation of 7-EC to hydroxycoumarin was likely to be CYP1B1, which was expressed at good levels (Figure 2A). The glucuronidation of HC is reported to be mediated by UGT1A6 (Lampe et al., 1999), which is also expressed at good levels in ORS-RHE models. There were six SULT isoforms (shown to be expressed in the ORS-RHE models in acetone treated control models (Figure 2B) which could have contributed to the sulfonation of $\mathrm{HC}$.

The amount of radioactivity applied that was recovered in the medium ranged between $60 \%$ and $82 \%$ of the applied dose (for all media samples and doses of 7-EC over $72 \mathrm{~h}$ ) and of this, 54-73\% was nonmetabolized 7-EC, indicating that this chemical does not require metabolism in order to pass through the epidermal layers into the medium (an observation also made previously (Jacques et al., 2010b)). This was the only one of the 4 test chemicals that was present as the parent chemical in significant amounts in the culture medium after $24 \mathrm{~h}$. There was a dose-dependent linear production of all three metabolites over 1 to 4 nmoles/model (Figure 6A), suggesting that the enzymes involved were not saturated, even at the highest 7-EC concentration used.. During the course of the $72 \mathrm{~h}$ incubation, the production of $\mathrm{HC}$ was maximal at $24 \mathrm{~h}$ but decreased thereafter, most likely due to further conjugation to HC-sulfate and HC-glucuronide. Interestingly, the production of $\mathrm{HC}$-sulfate and $\mathrm{HC}$-glucuronide reached a plateau after $48 \mathrm{~h}$ (Supplementary Figure 1A), which we attributed to the short residence time of 7-EC in the RHE models, 
such that once it had reached the culture medium, no further metabolism was possible. Comparatively less of the O-deethylated metabolite was detected in the medium, which may be due to its slow rate of formation compared to the faster rate of its conjugation into the HC-glucuronide and HC-sulfate.

\subsubsection{Testosterone}

Testosterone is hydroxylated by multiple CYPs and reduced by reductases, producing many metabolites in human liver microsomes and fresh human skin explants (Jacques et al., 2014). The major metabolites produced by human liver microsomes (Jacques et al., 2014) were also produced by the ORS-RHE models incubated in our studies, namely epiandrosterone (peak XII), androstenedione (peak XI), $\Delta 6$-testosterone (peak X), hydroxy- $\Delta 4$.dione (peaks IV, V' and VIII), 4-androsten-16 $\alpha$-ol-3,17-dione (peak VI) and 16 $\alpha$ hydroxytestosterone (peak III) (Figure 7B). One of the major metabolites formed in the ORS-RHE models was androsterone (peak XIII), the production of which is catalyzed by CYP2C18/19 (Yengi, 2003), neither of which were included in our gene analysis. Two other hydroxylated metabolites were produced in ORS-RHE tissues, 7 $\alpha$-hydroxytestosterone (peak I, produced by CYP2A6 and 2A13 (Bogaards et al., 2000; Desille et al., 1999)) and 6 $\beta$-hydroxytestosterone (peak II, produced by CYP1A1/2, CYP3A4/5/7 and CYP3A43 (Soucek et al, 2001; Waxman et al., 1991)), as well as a reduced metabolite, $5 \alpha$-androstan3,17-dione (peak XIII', catalysed by 5 $\alpha$-reductase (Liu and Yamauchi, 2008)).

Due to the multiple metabolites formed, we grouped them as either hydroxylated or reduced metabolites for the purpose of determining the dose and time dependence (Figure 7A). An interesting finding was that there was a more extensive production of hydroxylated metabolites of testosterone than reduced metabolites. This was also observed in ex vivo human skin and pig ear skin (Jacques et al, 2014) suggesting that this observation was not specific to our ORS-RHE model. Considering the lower CYP expression present in reconstructed skin models compared to reductases capacity, higher proportions of reduced metabolites would have been expected (van Eijl et al., 2012). Possible reasons for the relative 
contribution of hydroxylation and reduction pathways to testosterone metabolism could be due to the composition of the medium and/or the differences in the skin models. The hair follicle cells from which the RHE models are derived may exhibit XME profiles with predominant hydroxylation pathways, although this has not been confirmed with experimental data due to the low amount of cells in the hair follicle samples.

The amount of radioactivity applied that was recovered in the medium ranged between $62 \%$ and $78 \%$ of the applied dose (for all media samples and doses of testosterone over $72 \mathrm{~h}$ ) and of this, only $2-4 \%$ was present as non-metabolized testosterone, indicating that this model molecule resided in the ORS-RHE model long enough to be subject to extensive metabolism. The production of all metabolites was both dose- and time-dependent (Figure 7 and Supplementary Figure 1B). While the increase in hydroxymetabolite formation was linear (and not saturated) over this dose range, the rate of production of reduced metabolites decreased as the dose increased, suggesting these enzymes were saturated at higher doses. Non-linear production of testosterone metabolites (including hydroxylated metabolites) and enzyme saturation was also previously observed using pig skin at higher doses (400 - 800 nmoles/skin explant (Jacques et al., 2014)). The percentage of reduced metabolites also decreased over time (from $25 \%$ after $24 \mathrm{~h}$ to $17 \%$ and $13 \%$ after $48 \mathrm{~h}$ and $72 \mathrm{~h}$, respectively, suggesting that these metabolites are metabolized further within the incubation duration (Figure 7 and Supplementary Figure 1B). The percentage of hydroxylated metabolites increased from $34 \%$ after $24 \mathrm{~h}$ to $48 \%$ and $54 \%$ after $48 \mathrm{~h}$ and $72 \mathrm{~h}$, respectively, suggesting that the rate of metabolism decreased after $48 \mathrm{~h}$ following testosterone application.

\subsubsection{Benzo(a)pyrene (B(a)P)}

$\mathrm{B}(\mathrm{a}) \mathrm{P}$ was selected as a test chemical because its metabolism is more complex than 7-EC and because the penetration of this lipophilic compound is highly dependent on its metabolism such that only the metabolites of this chemical penetrate into the receptor fluid (Jacques et al., 2010a). Likewise, in the 
current study, only $1-3 \%$ of the radioactivity present in the culture medium was found to correspond to non-metabolized B(a)P. Between $9 \%$ and $21 \%$ of the applied dose was recovered in media samples for all doses of $\mathrm{B}(\mathrm{a}) \mathrm{P}$ over $72 \mathrm{~h}$, the majority of $\mathrm{B}(\mathrm{a}) \mathrm{P}$ being metabolized in the first $24 \mathrm{~h}$ (Supplementary Figure 1C). Although the synthetic standards for some metabolites were not available, there was enough of each $\mathrm{B}(\mathrm{a}) \mathrm{P}$ metabolite produced to be able to identify them by mass spectrometry and NMR. B(a)P was metabolized by ORS-RHE models to hydroxide, diol, catechol and dione metabolites (Figure 8B). The same metabolites are also produced by human liver microsomes (Jacques et al., 2010a) and are mainly produced by CYP1B1, CYP1A1 and microsomal epoxide hydrolases (EPHX) (Hvastkovs et al., 2007) and in part by CYP2C9, and CYP3A4 (Gautier et al., 1996). Of these XMEs, only CYP1B1 and EPHX were found to be expressed at the gene level in solvent control RHE tissues. Therefore, these isoforms are likely to be responsible for the CYP-mediated metabolism of $\mathrm{B}(\mathrm{a}) \mathrm{P}$, at least in the first few hours of the incubation. It is likely that CYP1A1 is also induced by $\mathrm{B}(\mathrm{a}) \mathrm{P}$ since this is an $\mathrm{AhR}$ ligand with similar inducing effects to $\beta \mathrm{NF}$ and 3-MC; therefore, this CYP may contribute to $\mathrm{B}(\mathrm{a}) \mathrm{P}$ metabolism once it has been induced.

The main phase II metabolites of $\mathrm{B}(\mathrm{a}) \mathrm{P}$ produced in ORS-RHE models are the mono-glucuronide and mono-sulfate conjugates of $\mathrm{B}(\mathrm{a}) \mathrm{P}$-hydroxide (Figure 8B), which is consistent with the metabolites produced in ex vivo pig skin (Jacques et al., 2010a). B(a)P phase I metabolites are conjugated via UGTs (1A9, 1A6 ,1A1) (Bock et al., 1999; Bock and Kohle, 2005; Girard et al., 2008) and the phenolconjugating SULT forms (SULT1A1, 1B1, 1A3) and SULT1E1 (Meinl et al., 2008). Of these, UGT1A6 was present, along with UGT1A10, 1A7 and 1A8, and SULT1A3 and 1E1 were present in ORS-RHE models.

The production of phase I metabolites of $\mathrm{B}(\mathrm{a}) \mathrm{P}$ was dose-dependent and linear over the dose range tested (Figure 8A). By contrast, sulfation and glucuronidation pathways were saturated at doses higher than 1 nmole since the amount of these conjugated metabolites produced reached a plateau at this dose. 


\subsubsection{3-Me thylcholanthre ne (3-MC)}

The metabolic activation of 3-MC to DNA reactive metabolites involves CYP1 XMEs (Guengerich, 1992). The primary metabolites are hydroxides, 1-hydroxy-3-MC and 2- hydroxy-3-MC, which are further metabolized to 1-keto-3-MC, and cholanthrene (Myers et al., 1989, Myers and Flesher, 1990), epoxides (which are then hydrolyzed (Stoming et al., 1977)) and a number of multiple-hydroxylated metabolites, including trans-1,2-dihydroxy-MC and 11,12- dihydroxy-11,12-dihydro-MC (Clayton and Clayton, 19811982). The hydroxides are subsequently conjugated to sulfates and glucuronides. The sulfated conjugates are reported to be more mutagenic than the hydroxides (Flesher et al., 1998) and the SULTs involved in the bioactivation depend on the hydroxide conjugated: SULT1B1 is primarily responsible for the activation of 1-hydroxy-3-MC (with SULT1C3 and SULT2A1 playing a minor role) and SULT1A1 is primarily responsible for the activation of 2-hydroxyl-3-MC (with SULT1A2 and SULT2A1 playing a minor role) (Meinl et al., 2013). Interestingly, none of these SULT isoforms were present at the gene level in the ORS-RHE models (Figure 2B); which suggests either that another isoform was responsible for the sulfo-conjugation of 3-MC metabolites or that the gene level of these XMEs does not correlate with their functional activities. The standard synthetic metabolites of 3-MC were not available and the low amount produced $(<10 \mu \mathrm{g})$ did not allow NMR identification. Therefore, we were unable to determine the exact position of hydroxyl functions nor conjugation positions, and denoted these metabolites either as "hydroxylated" or "reduced" metabolites (Figure 9A). Detoxification via epoxide hydrolases in the ORSRHE models is likely to be via EPHX1, which was expressed in these tissues. As with the other 3 chemicals, UGTs were involved in the detoxification of 3-MC. Interestingly, we found that 3-MC induced UGTs at the gene level after topical application (see Figure 5B) and these conjugates were readily detected after $24 \mathrm{~h}$ incubation of 3-MC with ORS-RHE models.

The amount of radioactivity applied that was recovered in the medium ranged between $55 \%$ and $78 \%$ of the applied dose (for all media samples and doses of 3-MC over $72 \mathrm{~h}$ ) and of this, only $2-4 \%$ was present 
as non-metabolized 3-MC, indicating that this chemical resided in the RHE models long enough to be subject to extensive metabolism. In contrast to $\mathrm{B}(\mathrm{a}) \mathrm{P}$, the formation of hydroxylated 3-MC metabolites was lower than the formation of phase II metabolites (glucuronidated and sulfated conjugates) (Figure 6). 3-MC phase I metabolites are conjugated via UGTs (1A5, 1A7, 1A6, 1A1) (Grams et al, 2000, Finel et al, 2005) and the SULTs involved in the formation of the sulfated conjugates are SULT1B1, SULT1C3, SULT2A1, SULT1A2 and SULT1A1 (Meinl et al., 2013). Interestingly, none of these SULT isoforms were present at the gene level in the ORS-RHE models (Figure 2B). Of the UGTs, UGT1A5, UGT1A6 and UGT1A7 were present at the gene level in the ORS-RHE models (Figure 2B). Interestingly, the gene expression of UGT1A8 and UGT1A10 were induced after topical application of 3-MC but they have not been reported as UGT enzymes involved in the 3-MC metabolism in the literature.

\section{Conclusions}

The aims of the current studies were to make a comprehensive characterization of the gene expression and functional activity of XMEs in ORS-RHE models and to characterize them as a suitable surrogate for native human skin for metabolism assays. Such models are important in the safety assessment of topically applied chemicals by enabling the measurement of potential metabolic activation to toxic metabolites or, conversely, detoxification, both of which impact local skin and systemic toxicity. This model reflects skin metabolism under realistic exposure scenarios and is more predictive than using extrapolations from liver test systems, which do not have the same XME profiles as skin (van Eijl et al., 2012) and cannot be modified to mimic topical application.

Our data showed that the ORS-RHE model is a novel alternative approach with extensive xenobiotic metabolism capabilities. Therefore, it could represent a complementary model to the commercially available epidermal models. The use of the ORS of the hair follicle is a new concept that allows for flexibility in the selection of the donor, especially of an adult skin source. Although several commercial models, made under controlled conditions, are available and are suited to a number of different assay 
endpoints (e.g. genotoxicity (Aardema et al., 2013), skin corrosion/irritation (Alépée et al., 2015)), we noted that XMEs profiles were more sensitive than other endpoints such that the reproducibility of data was affected by transportation conditions e.g. the duration of transport to our laboratory and seasonal variations. Therefore, an important aspect of this model is that it is generated within our laboratory and therefore exclude differences in enzymes functionality due to transport effects. Since topical application is the most relevant exposure route for cosmetics ingredients and for environmental pollutants, we also wanted to investigate whether topical application of test compounds could be employed in such assays.

The ORS-RHE model has a XME profile that is consistent with native human skin, supported by the presence of many of the Phase 1 and 2 XMEs at the gene level which have been reported to be present in human native skin by at least one other laboratory (Table 1). The highest gene expression level of Phase I XMEs was observed for alcohol/aldehyde dehydrogenases and (carboxyl)esterases, which is consistent with the proteomic profile of XMEs in native human skin reported by van Eijl et al. (2012). Also in keeping with other reports, the levels of Phase II XMEs present were generally higher than those of Phase I XMEs, the highest levels were observed for GSTs (notably GSTP1) and transferases, including NAT1. Although the abundance of CYP enzymes is reported to be low in comparison with reductases, esterases and dehydrogenases (van Eijl et al., 2012), there are a number of CYPs that are consistently reported to be detected in native human skin. These were also present at the gene level in the ORS-RHE model and include: CYP1B1, CYP2C18, CYP2D6, CYP2S1, CYP3A5, CYP4B1, CYP4F3, CYP7B1, CYP26B1 and CYP27B1.

There is little information on the comparison of metabolites produced after systemic and topical application to epidermal models, and the epidermal XMEs bioavailability is often assumed to be sufficient. RHE models exhibit a reduced barrier function compared with that of native skin (Thakoersing et al., 2012), making them unsuitable for skin penetration studies but ideal for metabolism studies (since there is a higher bioavailability to the epidermal XMEs). Our study demonstrate that the ORS-RHE 
models are able to rapidly metabolize four test compounds within $24 \mathrm{~h}$ of topical application. The extent of metabolism was dependent on the metabolism by the XMEs and on the residence time within the model, which is in keeping with the internal exposure model described by Manwaring et al., (2015). The presence of functional CYPs was confirmed by the extensive CYP-mediated metabolism of 7-EC, testosterone, B(a)P and 3-MC. The metabolites produced after incubation with testosterone also indicates the presence of reductases such as $5 \alpha$-reductase, the presence of which is reported to be pivotal in the regulation of androgens in the skin which in turn regulates hair growth (Liu and Yamauchi, 2008).

Importantly, the model is responsive to prototypical CYP inducers, such that CYP1A1 and CYP1B1 are both potently induced by the AhR ligands, $\beta \mathrm{NF}$ and 3-MC. The induction of CYP1A1 and CYP1B1 was evident at the gene and enzyme activity level, which is of significance because gene expression levels do not necessarily correspond to functional XME activities (Hewitt et al., 2013). $\beta$ NF and 3-MC also induced a number of UGT isoforms, although the extent of induction was not as high (2- to 5-fold) as that for CYP1A1 and CYP1B1 (133- and 250-fold, respectively). The ORS-RHE models are intended for use in metabolism studies; therefore, it is important to confirm whether XMEs can be altered by the test compound itself i.e. autoinduction during the incubation period tested.

In conclusion, the ORS-RHE model was shown to express a number of important XMEs, which could be induced in response to the incubation with CYP inducers. Functional XME activities were also demonstrated using either systemic or topical application routes, supporting their use in cutaneous metabolism studies and the prediction of the systemic exposure to parent and/or metabolites after topical application. Such a reproducible model will be of interest when evaluating the cutaneous metabolism and potential toxicity of innovative active ingredients. 


\section{Acknowledgement}

The authors would like to thank Nicola Hewitt for providing writing support and for helpful discussions during the preparation of the manuscript.

Mass spectrometry analyses were achieved by the MetaToul-AXIOM platform (INRA, UMR1331 Toxalim, Toulouse, France), MetaboHUB-ANR-11-INBS-0010.

\section{References}

Aardema MJ, Barnett BB, Mun GC, Dahl EL, Curren RD, Hewitt NJ, Pfuhler S. Evaluation of chemicals requiring metabolic activation in the EpiDerm ${ }^{\mathrm{TM}} 3 \mathrm{D}$ human reconstructed skin micronucleus (RSMN) assay. Mutat Res. 2013, 750(1-2):40-9. doi: 10.1016/j.mrgentox.2012.08.009.

Alépée N, Grandidier MH, Tornier C, Cotovio J. An integrated testing strategy for in vitro skin corrosion and irritation assessment using SkinEthic ${ }^{\mathrm{TM}}$ Reconstructed Human Epidermis. Toxicol In Vitro. 2015, 29(7):1779-92. doi: 10.1016/j.tiv.2015.07.012.

Bacqueville D, Douki T, Duprat L, Rebelo-Moreira S, Guiraud B, Dromigny H, Perier V, Bessou-Touya $\mathrm{S}$, Duplan H. A new hair follicle-derived human epidermal model for the evaluation of sunscreen genoprotection. J Photochem Photobiol B. 2015, 151:31-8. doi: 10.1016/j.jphotobiol.2015.06.015.

Benhamou S, Reinikainen M, Bouchardy C, Dayer P, Hirvonen A. Association between lung cancer and microsomal epoxide hydrolase genotypes. Cancer Res. 1998, 58(23):5291-3.

Black AT, Gray JP, Shakarjian MP, Laskin DL, Heck DE, Laskin JD. Distinct effects of ultraviolet B light on antioxidant expression in undifferentiated and differentiated mouse keratinocytes. Carcinogenesis. 2008, 29(1):219-25.

Bock KW, Gschaidmeier H, HeelH, Lehmköster T, Münzel PA, Bock-Hennig BS. Functions and transcriptional regulation of PAH-inducible human UDP-glucuronosyltransferases. Drug Metab Rev. 1999, 31(2):411-22.

Bock KW, Köhle C. UDP-glucuronosyltransferase 1A6: structural, functional, and regulatory aspects. Methods Enzymol. 2005, 400:57-75.

Bogaards JJ, Bertrand M, Jackson P, Oudshoorn MJ, Weaver RJ, van Bladeren PJ, Walther B.

Determining the best animal model for human cytochrome P450 activities: a comparison of mouse, rat, rabbit, dog, micropig, monkey and man. Xenobiotica. 2000, 30(12):1131-52. doi:

$10.1080 / 00498250010021684$

Bronaugh RL, Stewart RF. Methods for in vitro percutaneous absorption studies IV: The flow-through diffusion cell. J Pharm Sci. 1985, 74(1):64-7.

Cheung C, Smith CK, Hoog JO, Hotchkiss SA. Expression and localization of human alcohol and aldehyde dehydrogenase enzymes in skin. Biochem Biophys Res Commun. 1999, 261(1):100-7. 
Clayton, GD, FE Clayton (eds.). Patty's Industrial Hygiene and Toxicology: Volume 2A, 2B, 2C: Toxicology. 3rd ed. New York: John Wiley Sons, 1981-1982, p. 3367.

Conney AH, Chang RL, Jerina DM, Wei SJ. Studies on the metabolism of benzo[a]pyrene and dosedependent differences in the mutagenic profile of its ultimate carcinogenic metabolite. Drug Metab Rev. 1994, 26(1-2):125-63.

De Kanter R, Olinga P, De Jager MH, Merema MT, Meijer DK, Groothius GM. Organ slices as an in vitro test system for drug metabolism in human liver, lung and kidney. Toxicol In Vitro. 1999, 13(4-5):737-44.

Desille M1, Corcos L, L'Helgoualc'h A, Frémond B, Campion JP, Guillouzo A, Clément B. Detoxifying activity in pig livers and hepatocytes intended for xenotherapy. Transplantation. 1999 Nov 27;68(10):1437-43.

Edwards RJ, Adams DA, Watts PS, Davies DS, Boobis AR. Development of a comprehensive panel of antibodies against the major xenobiotic metabolizing forms of cytochrome P450 in humans. Biochem Pharmacol. 1998, 56:377-387.

Eilstein J, Léreaux G, Arbey E, Daronnat E, Wilkinson S, Duché D. Xenobiotic metabolizing enzymes in human skin and SkinEthic reconstructed human skin models. Exp Dermatol. 2015, 24(7):547-9. doi: 10.1111/exd.12694.

Finel M, Li X, Gardner-Stephen D, Bratton S, Mackenzie PI, Radominska-Pandya A.Human UDPglucuronosyltransferase 1A5: identification, expression, and activity. J Pharmacol Exp Ther. 2005, 315(3):1143-9. doi: 10.1124/jpet. 105.091900

Flesher JW, Horn J, Lehner AF. Carcinogenicity of 1-hydroxy-3-methylcholanthrene and its electrophilic sulfate ester 1-sulfooxy- 3-methylcholanthrene in Sprague-Dawley rats. Biochem Biophys Res Commun. 1998, 243:30-35.

Gautier JC, Urban P, Beaune P, Pompon D. Simulation of human benzo[a]pyrene metabolism deduced from the analysis of individual kinetic steps in recombinant yeast, Chem Res Toxicol. 1996, 9(2):418-425.

Girard H, Butler LM, Villeneuve L, Millikan RC, Sinha R, Sandler RS, Guillemette C. UGT1A1 and UGT1A9 functional variants, meat intake, and colon cancer, among Caucasians and African-Americans. Mutat Res. 2008, 644(1-2):56-63. doi: 10.1016/j.mrfmmm.2008.07.002.

Götz C, Hewitt NJ, Jermann E, Tigges J, Kohne Z, Hübenthal U, Krutmann J, Merk HF, Fritsche E. Effects of the genotoxic compounds, benzo[a]pyrene and cyclophosphamide on phase 1 and 2 activities in EpiDerm $^{\mathrm{TM}}$ models. Xenobiotica. 2012, 42(6):526-37. doi: 10.3109/00498254.2011.643255.

Grams B, Harms A, Braun S, Strassburg CP, Manns MP, Obermayer-Straub P.Distribution and inducibility by 3-methylcholanthrene of family $1 \mathrm{UDP}$-glucuronosyltransferases in the rat gastrointestinal tract. Arch Biochem Biophys. 2000, 377(2):255-65. doi: 10.1006/abbi.2000.1777

Guengerich FP. Metabolic activation of carcinogens. Pharmacol Ther. 1992, 54:17-61.

Guiraud B, Hernandez-Pigeon H, Ceruti I, Mas S, Palvadeau Y, Saint-Martory C, Castex-Rizzi N, Duplan $\mathrm{H}$, Bessou-Touya S. Characterisation of a human epidermis model reconstructed from hair follicle keratinocytes and comparison with two commercially models and native skin. Int J Cosmet Sci. 2014, 36:485-93. doi: 10.1111/ics.12150. 
Haag M, Hamann T, Kulle AE, Riepe FG, Blatt T, Wenck H, Holterhus PM, Peirano RI. Age and skin site related differences in steroid metabolism in male skin point to a key role of sebocytes in cutaneous hormone metabolism. Dermatoendocrinol. 2012, 4(1):58-64. doi: 10.4161/derm.19201.

Harris IR, Siefken W, Beck-Oldach K, Brandt M, Wittern KP, Pollet D. Comparison of activities dependent on glutathione S-transferase and cytochrome P-450 IA1 in cultured keratinocytes and reconstructed epidermal models. Skin Pharmacol Appl Skin Physiol. 2002,15(1):59-67.

Hewitt NJ, Edwards RJ, Fritsche E, Goebel C, Aeby P, Scheel J, Reisinger K, Ouédraogo G, Duche D, Eilstein J, Latil A, Kenny J, Moore C, Kuehnl J, Barroso J, Fautz R, Pfuhler S. Use of human in vitro skin models for accurate and ethical risk assessment:metabolic considerations. Toxicol Sci. 2013, 133(2):20917. doi: $10.1093 /$ toxsci/kft080.

Hikima T, Maibach HI. Gender differences of enzymatic activity and distribution of 17betahydroxysteroid dehydrogenase in human skin in vitro. Skin Pharmacol Physiol. 2007, 20(4):168-74.

Hu T, Khambatta ZS, Hayden PJ, Bolmarcich J, Binder RL, Robinson MK, Carr GJ, Tiesman JP, Jarrold BB, Osborne R, Reichling TD, Nemeth ST, Aardema MJ. Xenobiotic metabolism gene expression in the EpiDermin vitro 3D human epidermis model compared to human skin. Toxicol In Vitro. 2010, 24(5):1450-63. doi: 10.1016/j.tiv.2010.03.013.

Hvastkovs EG, So M, Krishnan S, Bajrami B, Tarun M, Jansson I, Schenkman JB, Rusling JF. Electrochemiluminescent arrays for cytochrome P450-activated genotoxicity screening. DNA damage from benzo[a]pyrene metabolites. Anal Chem. 2007, 79(5):1897-906. Erratum in: Anal Chem. 2008, 80(6):2272.

Imai T. Human carboxylesterase isozymes: catalytic properties and rational drug design. Drug Metab Pharmacokinet. 2006, 21(3):173-85.

Jäckh C, Blatz V, Fabian E, Guth K, van Ravenzwaay B, Reisinger K, Landsiedel R.. Characterization of enzyme activities of Cytochrome P450 enzymes, Flavin-dependent monooxygenases, N-acetyltransferases and UDP-glucuronyltransferases in human reconstructed epidermis and full-thickness skin models. Toxicol In Vitro. 2011, 25(6):1209-14. doi: 10.1016/j.tiv.2011.03.012.

Jacques C, Perdu E, Duplan H, Jamin EL, Canlet C, Debrauwer L, Cravedi JP, Mavon A, Zalko D. Disposition and biotransformation of 14C-Benzo(a)pyrene in a pig ear skin model: ex vivo and in vitro approaches. Toxicol Lett. 2010a, 199(1):22-33. doi: 10.1016/j.toxlet.2010.08.001.

Jacques C, Perdu E, Dorio C, Bacqueville D, Mavon A, Zalko D. Percutaneous absorption and metabolism of [14C]-ethoxycoumarin in a pig ear skin model. Toxicol In Vitro. 2010b, 24(5):1426-34. doi: 10.1016/j.tiv.2010.04.006.

Jacques C, Perdu E, Jamin EL, Cravedi JP, Mavon A, Duplan H, Zalko D. Effect of skin metabolism on dermal delivery of testosterone: qualitative assessment using a new short-term skin model. Skin Pharmacol Physiol. 2014, 27(4):188. doi: 10.1159/000351683.

Kawakubo Y, Yamazoe Y, Kato R, Nishikawa T: High capacity of human skin for N-acetylation of arylamines. Skin Pharmacol. 1990, 3:180-5.

Lampe JW, Bigler J, Horner NK, Potter JD. UDP-glucuronosyltransferase (UGT1A1*28 and UGT1A6*2) 
polymorphisms in Caucasians and Asians: relationships to serum bilirubin concentrations. Pharmacogenetics. 1999, 9(3):341-9.

Li W, Harper PA, Tang BK, Okey AB. Regulation of cytochrome P450 enzymes by aryl hydrocarbon receptor in human cells: CYP1A2 expression in the LS180 colon carcinoma cell line after treatment with 2,3,7,8-tetrachlorodibenzo-p-dioxin or 3-methylcholanthrene. Biochem Pharmacol. 1998, 56(5):599-612.

Liu S, Yamauchi H. Different patterns of 5alpha-reductase expression, cellular distribution, and testosterone metabolism in human follicular dermal papilla cells. Biochem Biophys Res Commun. 2008, 368(4):858-64. doi: 10.1016/j.bbrc.2008.01.130.

Lockley DJ, Howes D, Williams FM. Percutaneous penetration and metabolism of 2-butoxyethanol. Arch Toxicol. 2004, 78:617-28.

Luu-The V, Duche D, Ferraris C, Meunier JR, Leclaire J, Labrie F. Expression profiles of phases 1 and 2 metabolizing enzymes in human skin and the reconstructed skin models Episkin and full thickness model from Episkin. J Steroid Biochem Mol Biol. 2009, 116(3-5):178-86. doi: 10.1016/j.jsbmb.2009.05.011.

Manwaring J, Rothe H, Obringer C, Foltz DJ, Baker TR, Troutman JA, Hewitt NJ, Goebel C.

Extrapolation of systemic bioavailability assessing skin absorption and epidermal and hepatic metabolism of aromatic amine hair dyes in vitro. Toxicol Appl Pharmacol. 2015, 287(2):139-48. doi: 10.1016/j.taap.2015.05.016.

Meinl W, Ebert B, Glatt H, Lampen A. Sulfotransferase forms expressed in human intestinal Caco-2 and TC7 cells at varying stages of differentiation and role in benzo[a]pyrene metabolism. Drug Metab Dispos. 2008, 36(2):276-83. doi: 10.1124/dmd.107.018036

Meinl W, Tsoi C, Swedmark S, Tibbs ZE, Falany CN, Glatt H. Highly selective bioactivation of 1- and 2hydroxy-3-methylcholanthrene to mutagens by individual human and other mammalian sulphotransferases expressed in Salmonella typhimurium. Mutagenesis. 2013, 28(5):609-19. doi: 10.1093/mutage/get039.

Myers SR, Blake JW, Flesher JW. Metabolism of 3-methylcholanthrene in rat liver cytosol. Chem Biol Interact. 1989, 71(4):393-401.

Myers SR, Flesher JW. Metabolism of the carcinogen 3-methylcholanthrene in human bone marrow preparations. Drug Metab Dispos. 1990, 18(5):664-9.

OECD, 2004a. Guidance document for the conduct of skin absorption studies. OECD series on testing and assessment (No. 28) 5 March, 2004.

OECD, 2004b. OECD guideline for the testing of chemicals. Skin absorption: in vitro method. 428. Adopted 13 April, 2004.

Oesch F, Fabian E, Oesch-Bartlomowicz B, Werner C, Landsiedel R. Drug-metabolizing enzymes in the skin of man, rat, and pig. Drug Metab Rev. 2007, 39(4):659-98. doi: 10.1080/03602530701690366

Oesch F, Fabian E, Guth K, Landsiedel R. Xenobiotic-metabolizing enzymes in the skin of rat, mouse, pig, guinea pig, man, and in human skin models. Arch Toxicol. 2014 Dec;88(12):2135-90. doi: 10.1007/s00204-014-1382-8.

Saeki M, Saito Y, Nagano M, Teshima R, Ozawa S, Sawada J. mRNA expression of multiple cytochrome 
p450 isozymes in four types of cultured skin cells. Int Arch Allergy Immunol. 2002, 127(4):333-6.

Shimada T, Gillam EM, Sutter TR, Strickland PT, Guengerich FP, Yamazaki H.. Oxidation of xenobiotics by recombinant human cytochrome P450 1B1. Drug Metab Dispos. 1997, 25(5):617-22.

Soucek P, Zuber R, Anzenbacherova E, Anzenbacher P, Guengerich FP. Minipig cytochrome P450 3A, 2A and 2C enzymes have similar properties to human analogs. BMC Pharmacol2001, 1:11.

Soars MG, Petullo DM, Eckstein JA, Kasper SC, Wrighton SA. An assessment of udpglucuronosyltransferase induction using primary human hepatocytes. Drug Metab Dispos. 2004, 32(1):140-8.

Stoming TA, Bronstein W, Bresnick E. The metabolism of 3-methylcholanthrene by rat liver microsomes - a reinvestigation. Biochem Biophys Res Commun. 1977, 2179(2):461-9.

Svensson CK. Biotransformation of drugs in human skin. Drug Metab Dispos. 2009 Feb;37(2):247-53. doi: $10.1124 / \mathrm{dmd} .108 .024794$.

Thakoersing VS, Danso MO, Mulder A, Gooris G, El Ghalbzouri A, Bouwstra JA. Nature versus nurture: does human skin maintain its stratum corneum lipid properties in vitro? Exp Dermatol. 2012, 21(11):86570. doi: $10.1111 /$ exd.12031.

van Eijl S, Zhu Z, Cupitt J, Gierula M, Götz C, Fritsche E, Edwards RJ. Elucidation of xenobiotic metabolism pathways in human skin and human skin models by proteomic profiling. PLoS One. 2012, 7(7):e41721. doi: 10.1371/journal.pone.0041721.

Yengi LG, Xiang Q, Pan J, Scatina J, Kao J, Ball SE, Fruncillo R, Ferron G, Roland Wolf C. Quantitation of cytochrome P450 mRNA levels in human skin. Anal Biochem. 2003 316(1):103-10.

Waxman DJ, Lapenson DP, Aoyama T, Gelboin HV, Gonzalez FJ, Korzekwa K. Steroid hormone hydroxylase specificities of eleven cDNA-expressed human cytochrome P450s. Arch Biochem Biophys. 1991, 290:160-166.

Wiegand C, Hewitt NJ, Merk HF, Reisinger K. Dermal xenobiotic metabolism: a comparison between native human skin, four in vitro skin test systems and a liver system. Skin Pharmacol Physiol. 2014, 27(5):263-75. doi: 10.1159/000358272. 


\section{Figure legends}

Figure 1 An overview of the generation of the ORS-RHE model and the incubation conditions for metabolism assays.

Figure 2. Basal gene expression of Phase I (A) and II (B) XME target genes in ORS-RHE tissues treated systemically with DMSO (1\% v/v final concentration) in the medium. The different levels of expression were assigned according the $\mathrm{Ct}$ as follows: no expression $(\square)=\mathrm{Ct}>32$; weak expression $(\square)=\mathrm{Ct} 30$ - 32; Good expression $(\square)=\mathrm{Ct} 25-30$ and strong expression $(\square)=\mathrm{Ct}<25$.

Figure 3. Effect of systemic application of $\beta \mathrm{NF}(\mathrm{A})$ and topical application of 3-MC (B) to the Phase I XME gene profile of ORS-RHE models. The gene profiles were measured $24 \mathrm{~h}$ after treatment with 25 $\mu \mathrm{M} \beta \mathrm{NF}$ in the medium or after topical application of $100 \mathrm{nmoles} / \mathrm{cm}^{2} 3-\mathrm{MC}$. Values are fold increase compared to control. The lines represent unity \pm 2 -fold. Symbols in red represent genes that were induced by more than 2-fold and symbols in blue represent genes that were decreased by more than 2-fold. XMEs in red indicate the change was statistically significant and XMEs in black indicate the change was not statistically significant.

Figure 4. EROD activity in ORS-RHE models treated systemically (A) or topically (B) with $\beta$ NF or 3-MC. EROD activity was measured $24 \mathrm{~h}$ after treatment with $25 \mu \mathrm{M} \beta \mathrm{NF}$ or $10 \mu \mathrm{M}$ 3-MC (systemic application) or after application of $100 \mathrm{nmoles} / \mathrm{cm}^{2}$ of $\beta \mathrm{NF}$ or 3-MC (topical application). EROD was expressed as the mean \pm standard error in pmoles $/ \mathrm{mg} / \mathrm{min}$. Data were obtained from 3 donors in triplicate and statistical analysis was calculated using a two-tailed Student's t-test. Differences were considered statistically significant from $\mathrm{p}<0.05$. NS not significant $\mathrm{p}>0.05, * \mathrm{p}<0.05, * * \mathrm{p}<0.01$ and $* * * \mathrm{p}<$ 0.001 . 
Figure 5. Effect of systemic application of $\beta \mathrm{NF}(\mathrm{A})$ and topical application of 3-MC (B) to the Phase II XME gene profile of ORS-RHE models. The gene profiles were measured $24 \mathrm{~h}$ after treatment with 25 $\mu \mathrm{M} \beta \mathrm{NF}$ in the medium or after topical application of $100 \mathrm{nmoles} / \mathrm{cm}^{2} 3-\mathrm{MC}$. Values are fold increase compared to control. The lines represent unity \pm 2 -fold. Symbols in red represent genes that were induced by more than 2-fold and symbols in blue represent genes that were decreased by more than 2-fold. XMEs in red indicate the change was significant and XMEs in black indicate the change was not statistically significant.

Figure 6. Dose-dependency (A) and radiochromatogram (B) of metabolite production in the medium $24 \mathrm{~h}$ after topical application of 7-EC. The doses applied were 1,2 and $4 \mathrm{nmoles} / \mathrm{cm}^{2}$. The amount of metabolites ( $n=3$ donors, mean \pm SEM) formed were HC $(\square$, peak not visible in chromatogram), HCglucuronide $(\mathrm{O}$, Peak I in radiochromatogram) and HC-sulfate (O, Peak II in radiochromatogram). The correlation coefficients $\left(\mathrm{R}^{2}\right)$ for the goodness of fit were $0.94,0.98$ and 0.86 for the HC, HC-glucuronide and HC-sulfate, respectively.

Figure 7. Dose-dependency (A) and radiochromatogram (B) of metabolite production in the medium $24 \mathrm{~h}$ after topical application of testosterone. The doses applied were 1,2 and $4 \mathrm{nmoles} / \mathrm{cm}^{2}$. The amount of metabolites $(\mathrm{n}=3$ donors, mean \pm SEM) shown in (A) are combined values for reduced $(\square)$ and hydroxylated $(\square)$ metabolites. The metabolites of testosterone shown in the radiochromatogram (B) are as

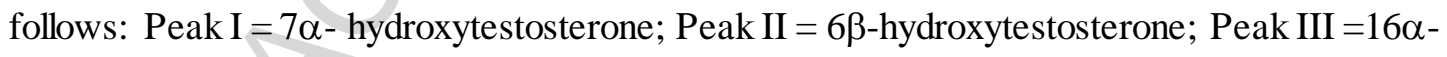
hydroxytestosterone; Peak IV = hydroxy-4-androstene-3,17-dione (standard not available); Peak V'= hydroxy-4-androstene-3,17-dione; Peak VI = 4-androsten-16 $\alpha$-ol-3,17-dione (16 $\alpha$-hydroxy-4-androstene3,17-dione); Peak VIII = hydroxy-4-androstene-3,17-dione (standard not available); Peak IX = hydroxytestosterone (standard not available); Peak $X=17 \beta$-hydroxyandrosta-4,6-dien-3-one $(\Delta 6$ testosterone); Peak XI = androstenedione; Peak XII = epiandrosterone; Peak XIII' $=5 \alpha$-androstan-3,17- 
dione and Peak XIII = androsterone. The correlation coefficients $\left(\mathrm{R}^{2}\right)$ for the goodness of fit were 0.97 and 0.98 for the reduced and hydroxylated metabolites, respectively.

Figure 8. Dose-dependency (A) and radiochromatogram (B) of metabolite production in the medium $24 \mathrm{~h}$ after topical application of B(a)P. The doses applied were 1,2 and $4 \mathrm{nmoles} / \mathrm{cm}^{2}$. The amount of metabolites ( $\mathrm{n}=3$ donors, mean \pm SEM) shown in (A) are combined values for Phase $\mathrm{I}(\square)$, glucuronidated $(\mathrm{O})$ and sulfated $(\mathrm{)})$ metabolites. The metabolites of $\mathrm{B}(\mathrm{a}) \mathrm{P}$ shown in the radiochromatogram $(\mathrm{B})$ are as follows: Peak I = B(a)P-diol-sulfate; Peak II = B(a)P-7,8,9,10-tetrol; Peak $\mathrm{III}=\mathrm{B}(\mathrm{a}) \mathrm{P}$-diol-glucuronide; Peak IV = B(a)P-O-glucuronide; Peak V = B(a)P-O-sulfate; Peak VI = $\mathrm{B}(\mathrm{a}) \mathrm{P}$-catechol; Peak VII = B(a)P-hydroxide. The correlation coefficients $\left(\mathrm{R}^{2}\right)$ for the goodness of fit were 1.00, 1.00 and 0.61 for the Phase I, HC-glucuronide and HC-sulfate, respectively.

Figure 9. Dose-dependency (A) and radiochromatogram (B) of metabolite production in the medium $24 \mathrm{~h}$ after topical application of 3-MC. The doses applied were 1,2 and 4 nmoles $/ \mathrm{cm}^{2}$. The amount of metabolites ( $n=3$ donors, mean \pm SEM) shown in (A) are combined values for Phase $\mathrm{I}(\square)$, glucuronidated $(\mathrm{O})$ and sulfated $(\mathrm{O})$ metabolites. The metabolites of 3-MC shown in the radiochromatogram (B) are as follows: Peaks I and II = 3-hydroxy-3MC-glucuronide; Peak III = 3hydroxy-3MC-sulfate; Peak IV = 2-hydroxy-3MC- glucuronide; Peak V = 3-hydroxy-3MC-sulfate and 2hydroxy-3MC- glucuronide; Peak VI = 2-hydroxy-3MC- glucuronide; Peak VII = 2-hydroxy-3MCsulfate $;$ Peak VIII = 2-hydroxy-3MC- glucuronide + 2-hydroxy-3MC- sulfate; Peak IX = 2-hydroxy3MC- sulfate; Peak X = 3-hydroxy-3MC- sulfate; Peaks XI and XII =3-hydroxy-3MC; Peak XIII = hydroxy-3MC- glucuronide; Peak XIV = 2-hydroxy-3MC ; Peak XV = Hydroxy-3MC-sulfate ; Peak XVI = 2-hydroxy-3MC; Peak XVII = hydroxy-3MC. The correlation coefficients $\left(\mathrm{R}^{2}\right)$ for the goodness of fit were $0.80,0.97$ and 0.98 for the Phase I, HC-glucuronide and HC-sulfate, respectively. 
Supplementary Figure 1. Time-dependency of metabolite production in the medium over $72 \mathrm{~h}$ after topical application of (A) 7-EC, (B) testosterone, (C) B(a)P and (D) 3-MC. The dose applied was 1 nmole $/ \mathrm{cm}^{2}\left(0.33 \mathrm{~cm}^{2}\right.$ disc area). The amount of parent and metabolites was expressed as the mean nmole produced $\pm \mathrm{SD}, \mathrm{n}=3$ (triplicate ORS-RHE models). The metabolites formed from 7-EC ( ) shown in (A) were HC $(\square)$, HC-glucuronide $(\bigcirc)$ and HC-sulfate $(\bigcirc)$. The metabolites formed from testosterone $(\diamond)$ shown in (B) are combined values for reduced $(\square)$ and hydroxylated $(\square)$ metabolites. The metabolites formed from $\mathrm{B}(\mathrm{a}) \mathrm{P}(\diamond)$ shown in $(\mathrm{C})$ are combined values for Phase $\mathrm{I}(\square)$, glucuronidated $(\mathrm{O})$ and sulfated $(\mathbf{O})$ metabolites. The metabolites from 3-MC ( $\boldsymbol{\Delta})$ shown in (D) are combined values for hydroxylated $(\bigcirc)$, glucuronidated $(\square)$ and sulfated $(\bigcirc)$ metabolites. 
A

Hair follicle-derived epidermis

hair follicl plucking

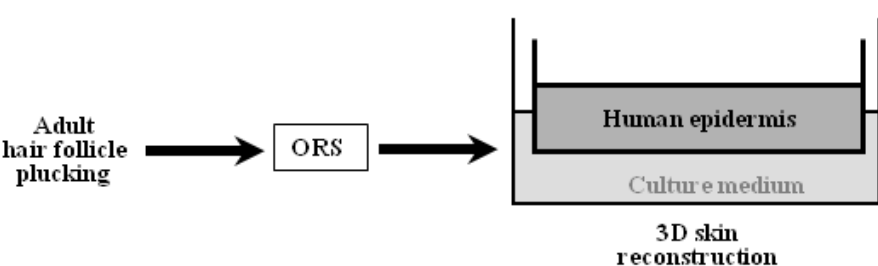

B Epidermal xenobiotic metabolism
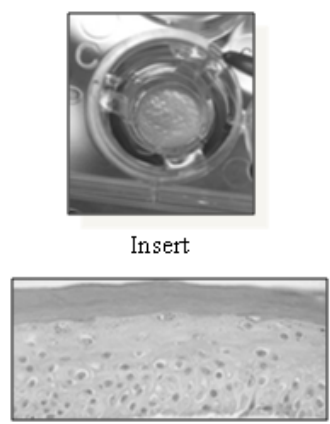

Histology

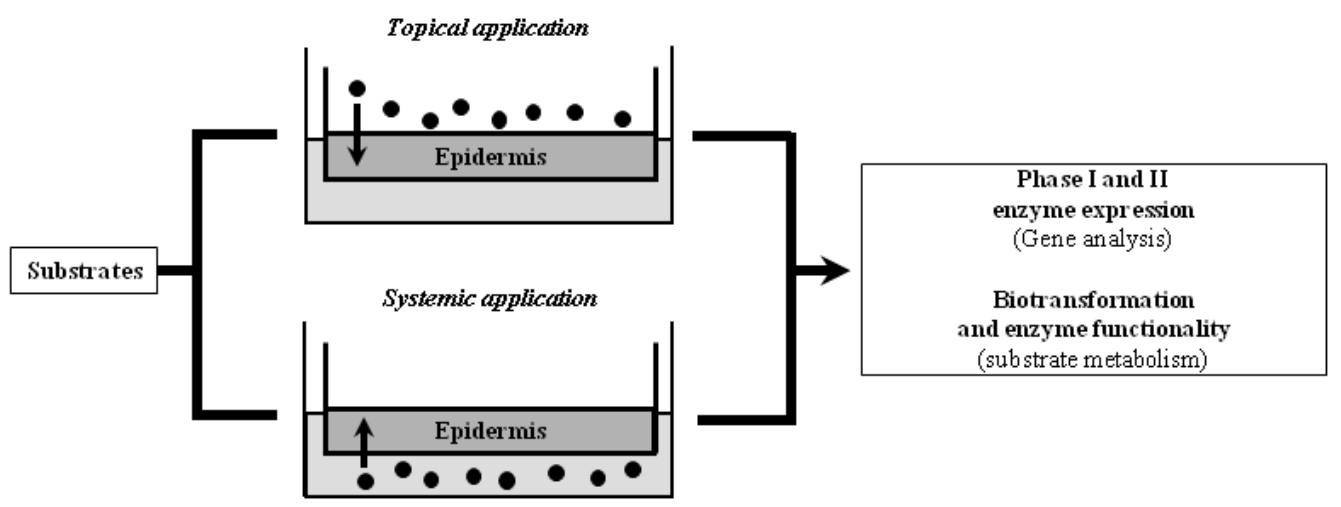

Fig. 1 
(A) Phase I XMEs

\begin{tabular}{|c|c|c|c|c|c|c|c|c|c|c|c|c|}
\hline \multicolumn{6}{|c|}{ CYPs } & $\begin{array}{l}\text { FMOs, } \\
\text { MOAs }\end{array}$ & ADHs & \multicolumn{2}{|c|}{ ALDHs } & Esterases & \multicolumn{2}{|c|}{ Other } \\
\hline CYP1A1 & CYP1A2 & CYP181 & CYP2A13 & CYP2B6 & CYP2CB & FMO1 & ADH1A & ALDH1A1 & MLDH1A2 & UCHL1 & EFHXX & EFHCO \\
\hline CYP2C9 & CYP2C18 & CYP2C19 & CYP2D6 & CYP2E1 & CYP2F1 & FMO2 & ADH1B & ALOH1A3 & ALDH1B1 & UCHL3 & cESI & CES2 \\
\hline CYP2R1 & CYP2S1 & CYP2W1 & CYP3,4 & CYP3A5 & CYP3A7 & FMO3 & ADHIC & ALH2 & ALDH3A1 & GZMA & CES3 & CES5A \\
\hline CYP3A43 & CYPAA11 & CYPAA22 & CYPAB1 & CYPAF2 & CYPAF3 & FMO4 & $\mathrm{ADH} 4$ & АLDH $3 A 2$ & ALDH381 & GZMB & NQ01 & $\mathrm{NQ02}$ \\
\hline CYPAFB & CrPAF11 & CYP4F12 & СYP7A1 & CYP781 & CYPBB1 & FMO5 & ADH5 & АLDH 382 & ALDHAM & CEL & PTGS1 & PTGSZ \\
\hline CYP11A1 & CYP11B1 & CYP11B2 & CYP17A1 & CYP19A1 & CYP21A2 & MAOA & $\mathrm{ADH} 6$ & ALOH5AM & ALOHGA1 & ESD & HSD17810 & DPYD \\
\hline CYP24A1 & CYP26A1 & CYP2681 & CYP26C1 & CYP27A1 & CYP2781 & MAOB & $\mathrm{ADH} 7$ & ALOH7A1 & ALDHBA1 & AADAC & XDH & DHRS2 \\
\hline & & & & & & & & АLOH9A & & & & \\
\hline
\end{tabular}

(B) Phase II XME s

\begin{tabular}{|c|c|c|c|c|c|c|c|c|c|c|c|}
\hline \multicolumn{3}{|c|}{ GSTs } & \multicolumn{2}{|c|}{ SULTs } & \multicolumn{3}{|c|}{ UGTs } & \multicolumn{3}{|c|}{ Transferasees } & Synthases \\
\hline GSTAI & GSTA3 & ESTA4 & SULTIAI & SULTIA? & UGTIAI & VETIA3 & UGTIA & NATI & NAT2 & NAA20 & AcsLl \\
\hline GSTA5 & ESTKI & ESTM2 & SULTIA3 & suLTIBI & UGTIA5 & UGTIA6 & UGIIA & AANAT & SATI & BAAT & $\operatorname{AcsL} 3$ \\
\hline GSTM3 & GSTM4 & GSTM5 & SULTICI & SULTIC2 & UGTIA8 & UGTIA9 & UGTIAIO & GYYAT & ASMT & AS3MT & ACSLA \\
\hline EST01 & EST02 & ESTI & SULTIC3 & SULTIE & UGT2Al & UGT2A3 & UGT2B10 & coMT & GNMT & EAMT & ACsMI \\
\hline ESTII & ESTT2 & & SULT2Al & SULT2B1 & UGT2B1? & UGT2B28 & UGT2BA & HNMT & INMT & NNMT T & ACsM2B \\
\hline mESTI & mGST2 & nGST3 & SULTAAI & SULT6BI & UGT2B? & UGT3AI & UGT8 & FNMT & TFT & & ACSM3 \\
\hline & & & 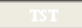 & & & & & AGXT & DDOST & CCBLI & $t=$ \\
\hline
\end{tabular}

Fig. 2 
(A) Systemic application of $\beta N F$

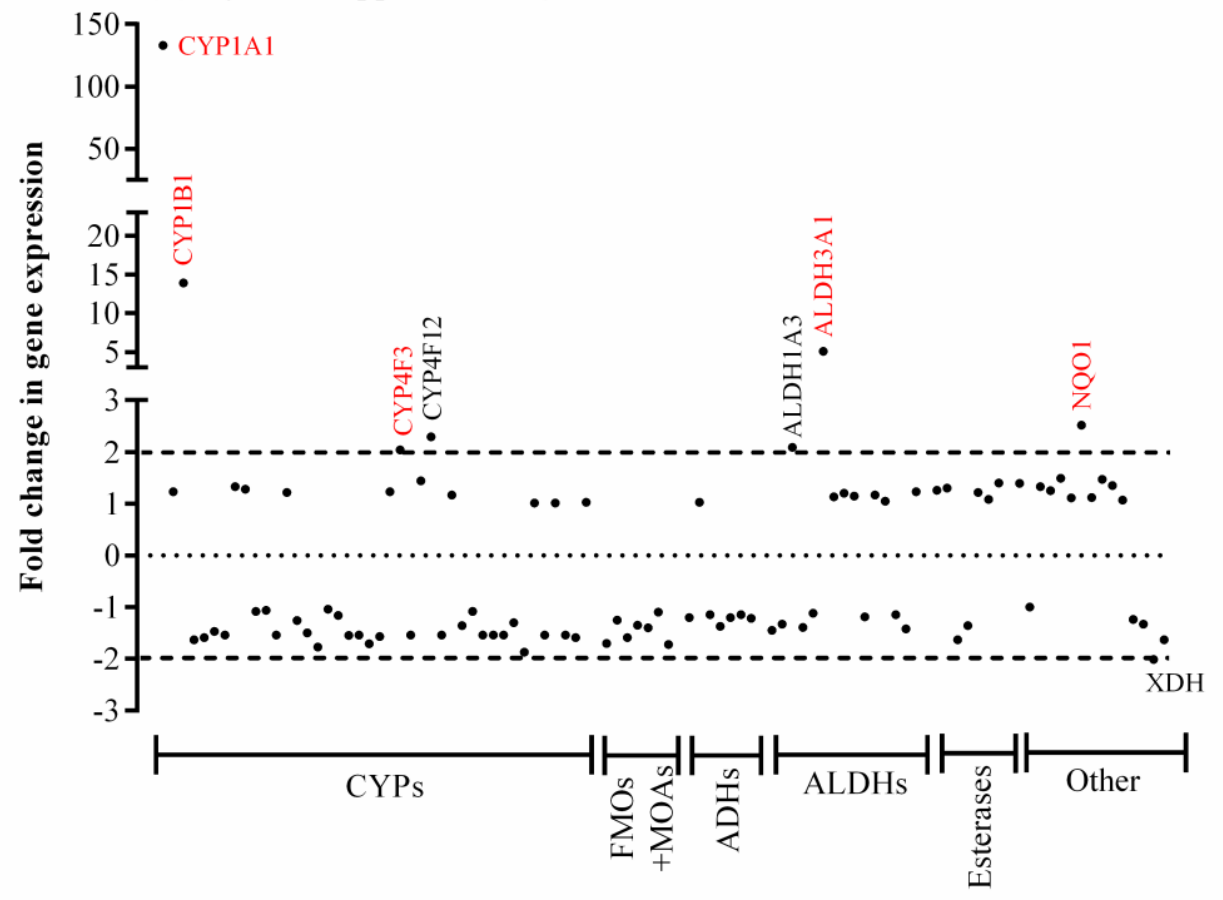

(B) Topical application of 3-MC

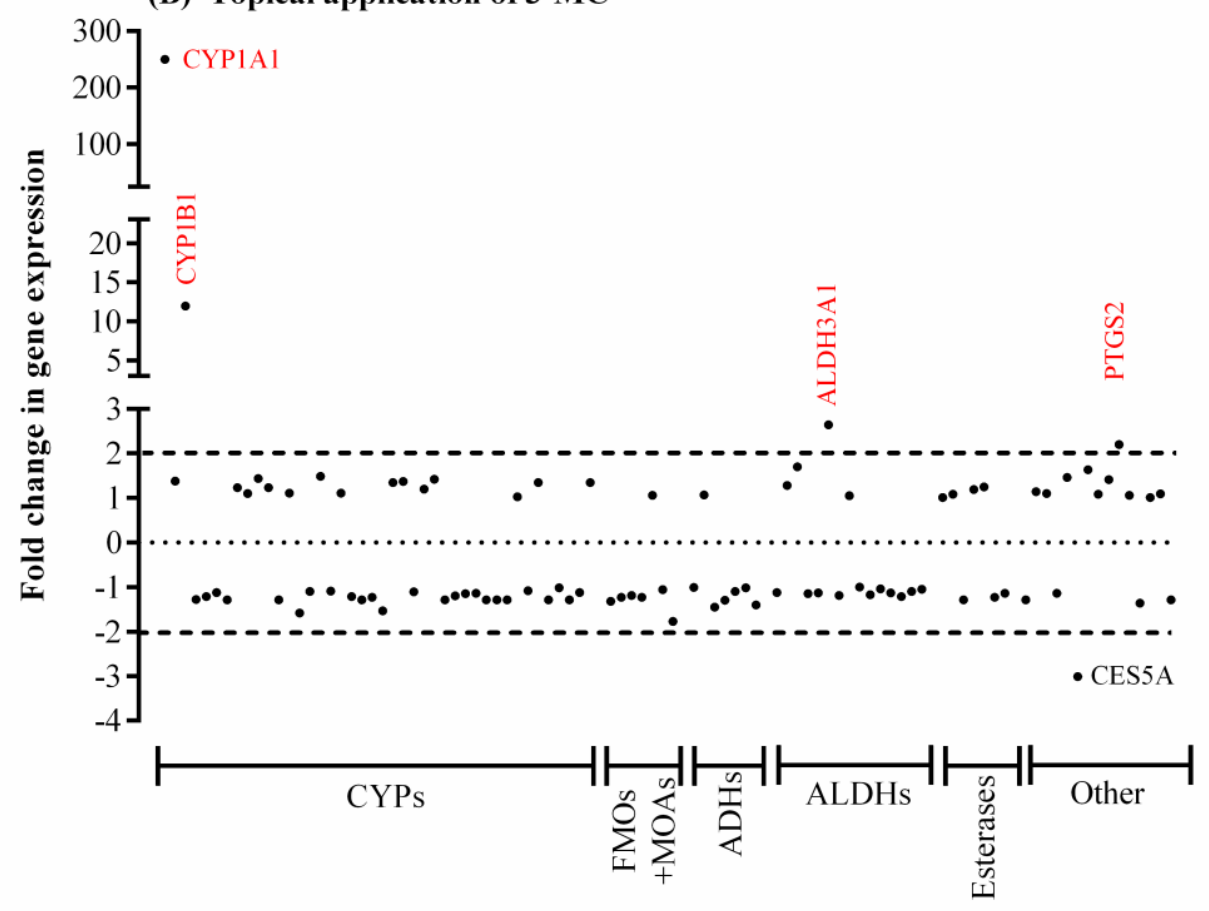

Fig. 3 
(A) Systemic application

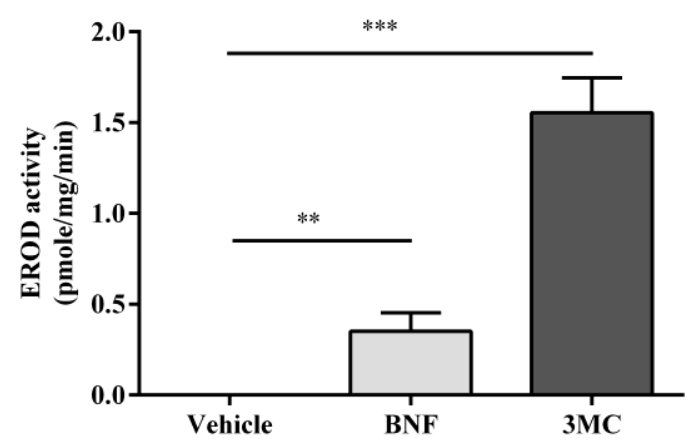

(B) Topical application

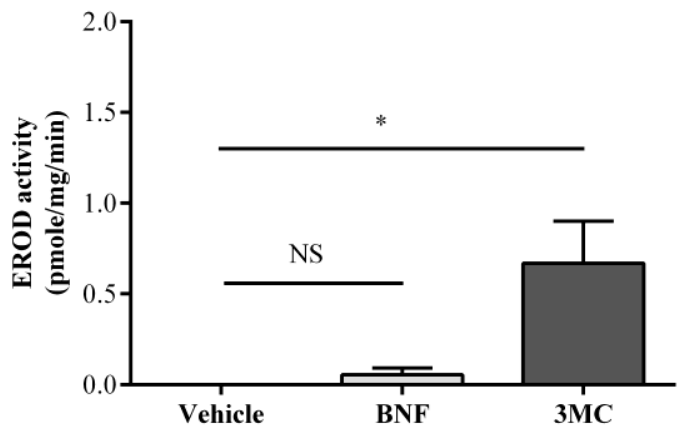

Fig. 4 
(A) Systemic application of $\beta \mathrm{NF}$

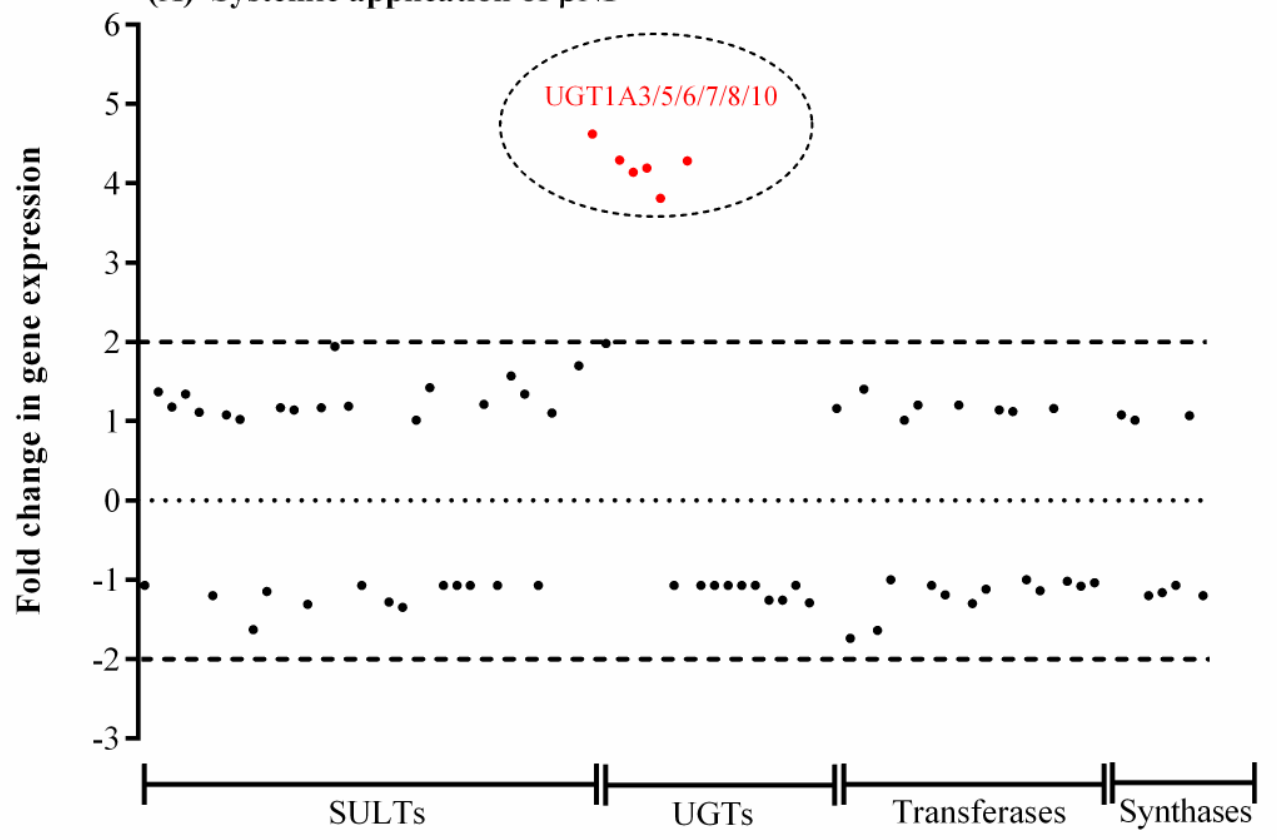

(B) Topical application of 3-MC

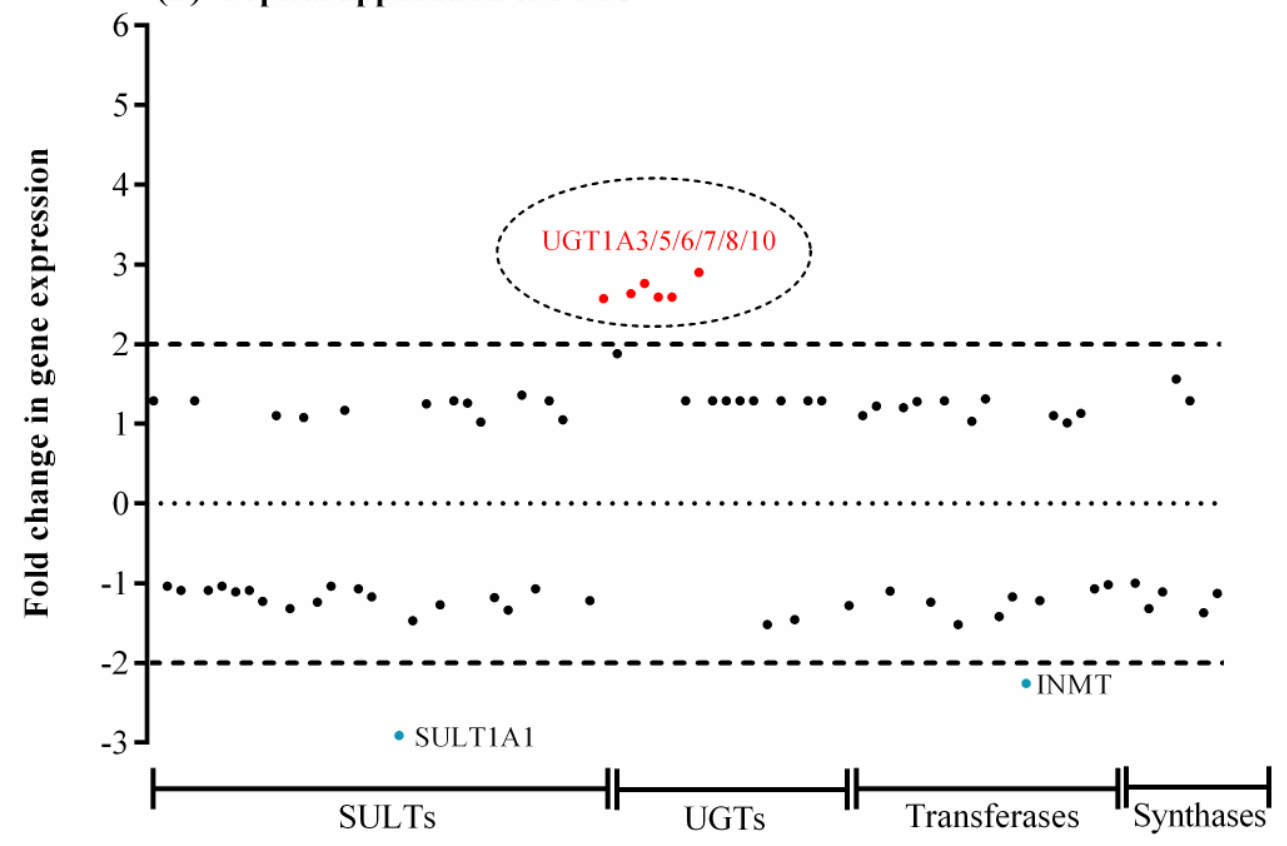

Fig. 5 
(A) Dose dependency of metaboliteformation

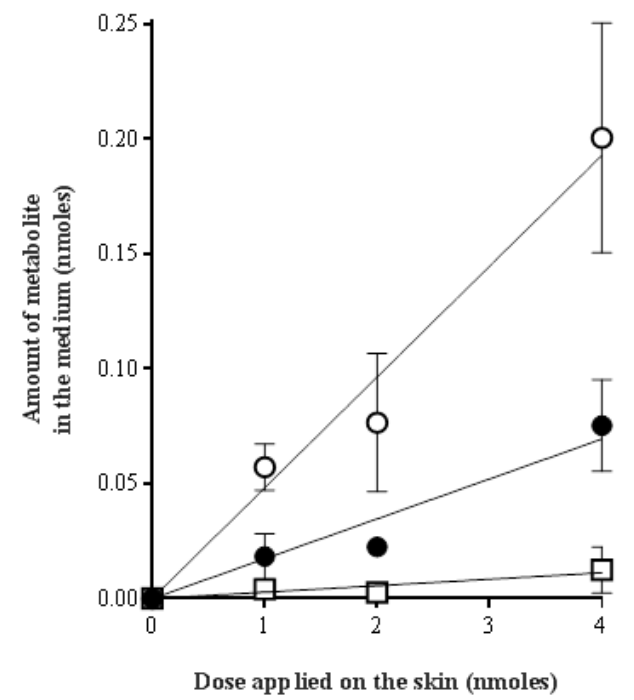

(B) Radiochr omatogram showing parent compound and metabolites

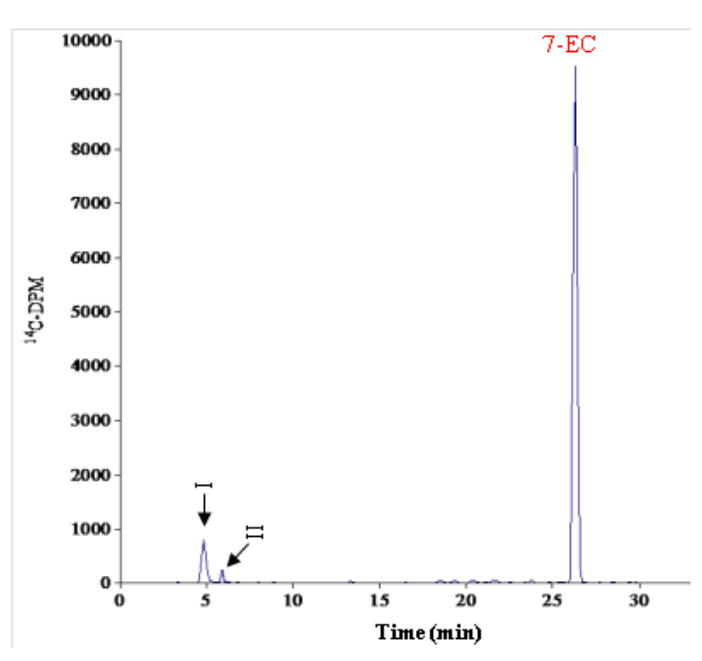

Fig. 6

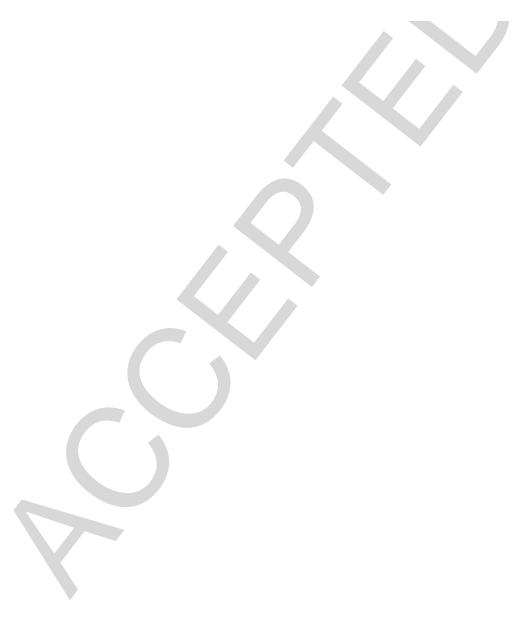




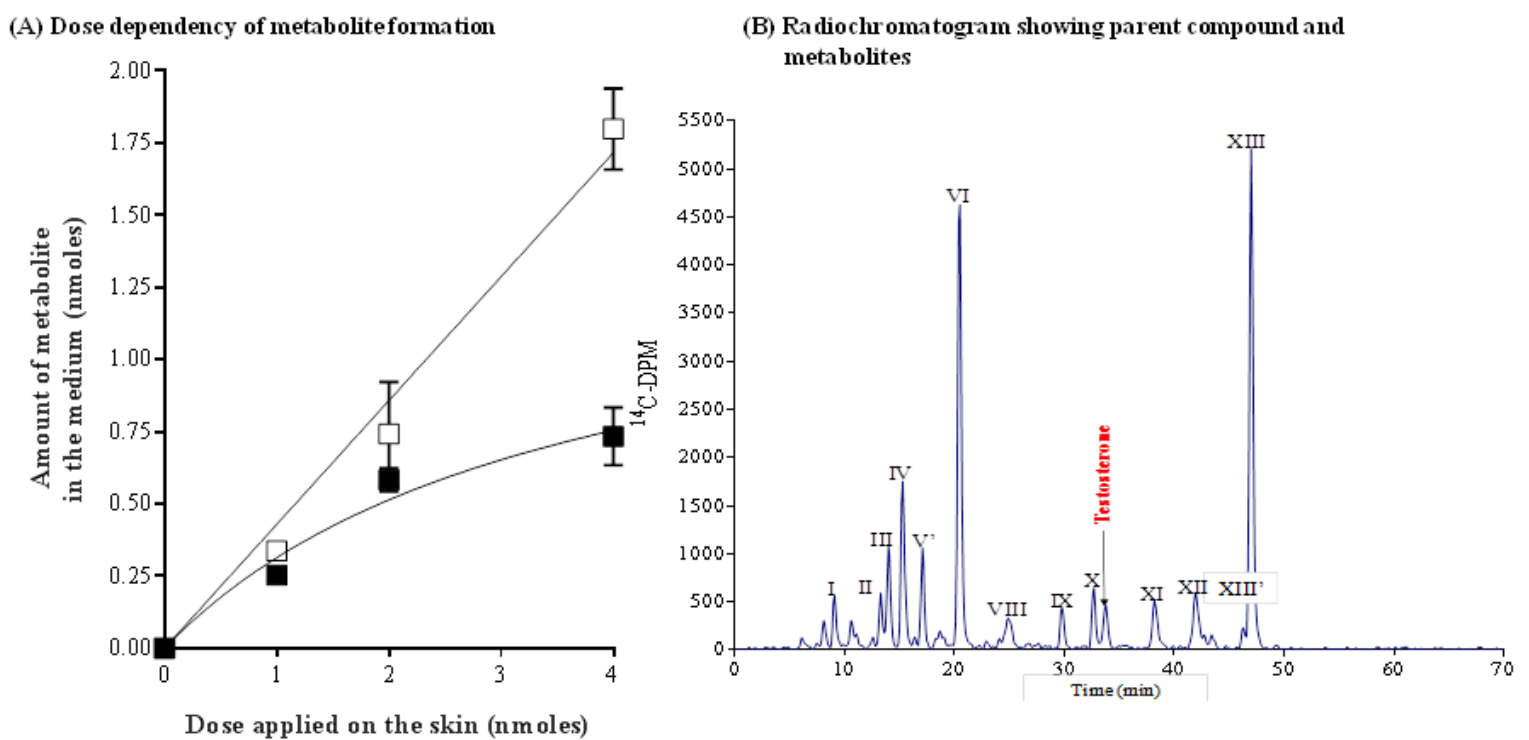

Fig. 7 
(A) Dose dependency of metaboliteformation

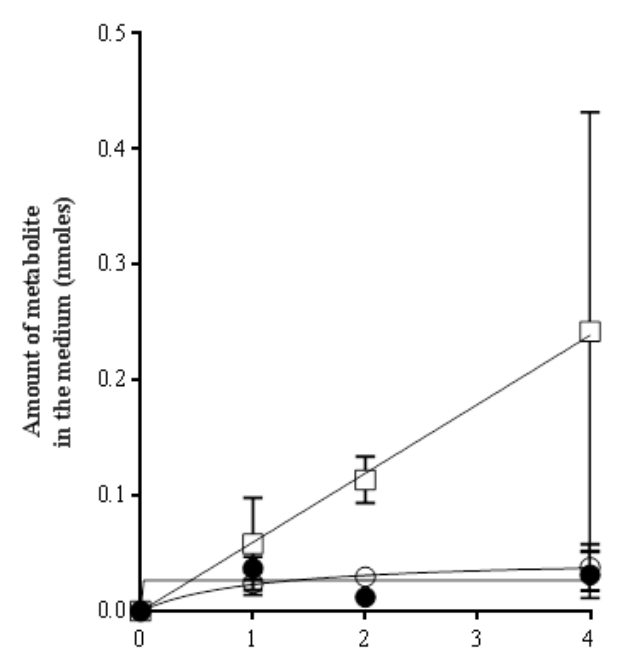

Dose applied on the skin (nmoles)
(B) Radiochromatogram showing parent compound metabolites

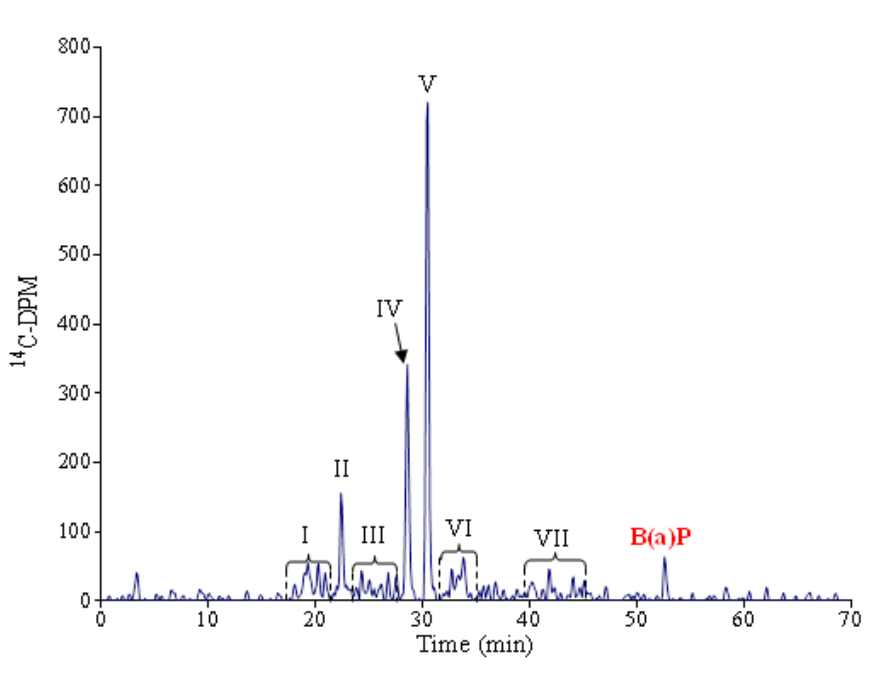

Fig. 8 

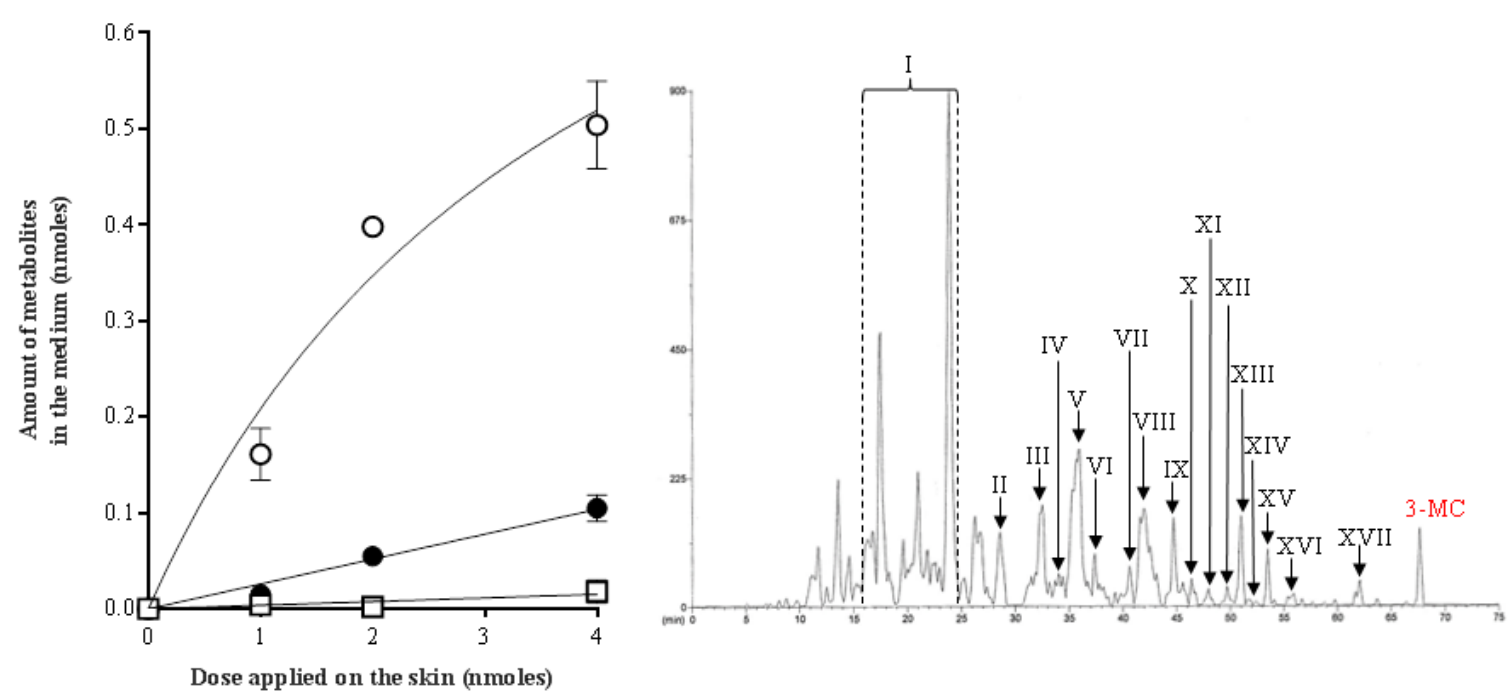

Fig. 9 
Table 1. Summary of XMEs identified in control ORS-RHE models that are present at the gene level in comparison to native human skin. Genes shown to be present in native human skin are from Luu-The et al. (2009), Hu et al. (2010), Wiegand et al. (2014) and Svensso (2009) and Oesch et al. (2014). + = present, = absent; $\mathrm{NR}=$ not reported; ND = Not determined; $\mathrm{a}=$ reported by Luu-The et al. (2009); $\mathrm{b}=$ reported by Hu et al. (2010).

\begin{tabular}{|c|c|c|}
\hline XME & $\begin{array}{l}\text { Native human } \\
\text { skin }\end{array}$ & $\begin{array}{l}\text { Control ORS- } \\
\text { RHE model }\end{array}$ \\
\hline \multicolumn{3}{|l|}{ Phase 1} \\
\hline CYP1A1 & + & - \\
\hline CYP1B1 & + & + \\
\hline CYP2C18 & + & + \\
\hline CYP2R1 & + & + \\
\hline CYP2S1 & + & + \\
\hline CYP3A5 & + & + \\
\hline CYP4B1 & + & + \\
\hline CYP4F2 & + & + \\
\hline CYP4F3 & + & 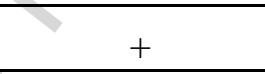 \\
\hline CYP4F11 & - & + \\
\hline CYP7B1 & + & + \\
\hline CYP19A1 & - & - \\
\hline CYP26B1 & + & + \\
\hline CYP27B1 & + & + \\
\hline $5 \alpha$-Reductase & + & ND \\
\hline FMO4 & 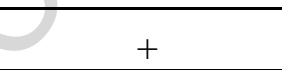 & + \\
\hline MAOA & NR & + \\
\hline ADH5 & - & + \\
\hline ALDH1A1/2/3 & + & + \\
\hline ALDH2 & + & + \\
\hline ALDH3A2 & + & + \\
\hline ALDH3B1/2 & + & + \\
\hline ALDH4A1/5A1/6A1 & NR & + \\
\hline ALDH7A1/9A1 & + & + \\
\hline UCHL1 & NR & + \\
\hline
\end{tabular}




\begin{tabular}{|l|c|c|}
\hline UCHL3 & NR & + \\
\hline ESD & NR & + \\
\hline EPX1 & + & + \\
\hline CES1/2/5A & + & + \\
\hline NQO1/2 & + & + \\
\hline PTGS1/2 & + & + \\
\hline HSD17B10 & NR & + \\
\hline DPYD & NR & + \\
\hline XHD & NR & + \\
\hline Phase 2 & + & + \\
\hline GST1A4 & NR & + \\
\hline GSTK1 & + & + \\
\hline GSTM2/3/4 & NR & + \\
\hline GSTO1/2 & + & + \\
\hline GSTP1 & + & + \\
\hline GSTT1 & + & + \\
\hline GSTT2 & + & + \\
\hline MGST1/2/3 & + & + \\
\hline SULT1A1 & NR & + \\
\hline SULT1A3 & + & + \\
\hline SULT1A5/8 & NR & + \\
\hline SULT1B1 & + & + \\
\hline SULT1E1 & + & + \\
\hline SULT2B1 & + & + \\
\hline TST & + & + \\
\hline UGT1A3/5/7 & + & + \\
\hline UGT1A6/8/10 & + & + \\
\hline NAT1 & + & + \\
\hline NAA20 & + & + \\
\hline SAT1 & + & + \\
\hline AS3MT & + & + \\
\hline COMT & + & + \\
\hline NAMT & + & + \\
\hline
\end{tabular}




\begin{tabular}{|l|l|c|}
\hline DDOST & NR & + \\
\hline CCBL1 & NR & + \\
\hline
\end{tabular}

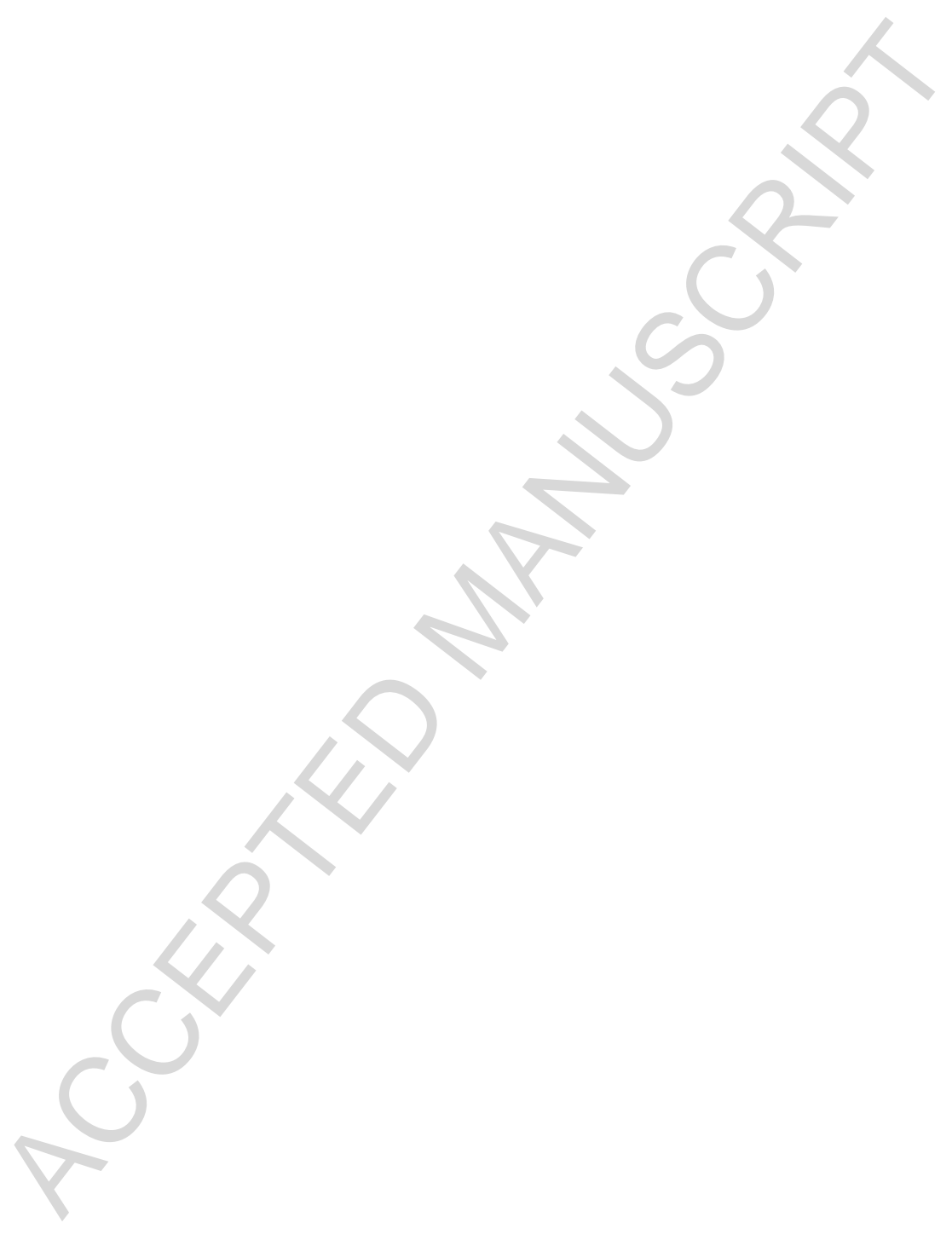




\section{Graphical abstract}
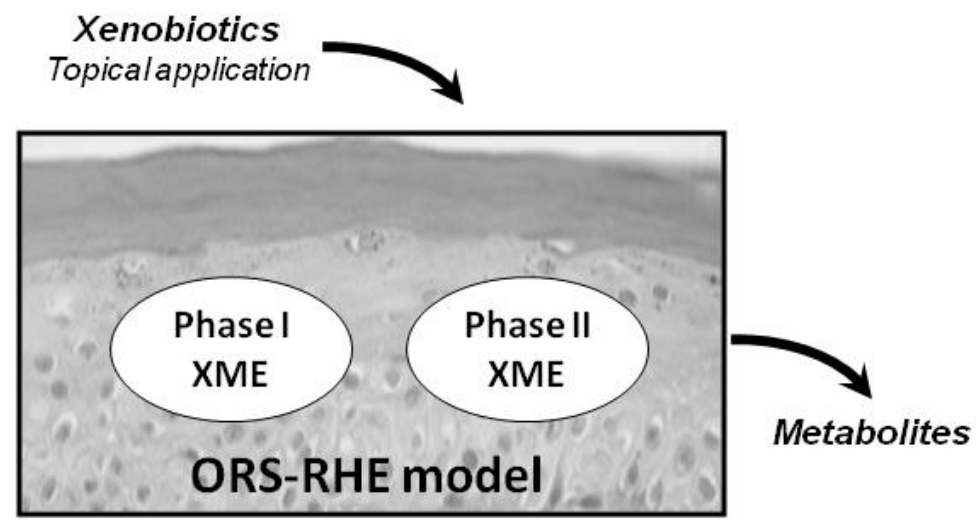

Xenobiotics

Systemic application

Graphical abstract 


\section{HIGHLIGHTS}

- Phase I and II xenobiotic metabolizing enzymes are expressed in ORS-RHE model derived from adult hair follicles

- Xenobiotic metabolizing enzymes are functional in ORS-RHE following either systemic or topical application

- Xenobiotic metabolizing enzymes are inducible in ORS-RHE

- ORS-RHE is a suitable model for studying skin metabolism

- ORS-RHE is a convenient and reliable tool for the evaluation of xenobiotics 